\title{
Mutational analysis of the C-terminal FATC domain of Saccharomyces cerevisiae Tra1
}

\author{
Stephen M. T. Hoke • A. Irina Mutiu • Julie Genereaux • \\ Stephanie Kvas • Michael Buck • Michael Yu • \\ Gregory B. Gloor $\cdot$ Christopher J. Brandl
}

Received: 8 April 2010 / Revised: 25 June 2010 / Accepted: 29 June 2010 / Published online: 16 July 2010

(C) The Author(s) 2010. This article is published with open access at Springerlink.com

\begin{abstract}
Tra1 is a component of the Saccharomyces cerevisiae SAGA and NuA4 complexes and a member of the PIKK family, which contain a C-terminal phosphatidylinositol 3-kinase-like (PI3K) domain followed by a 35-residue FATC domain. Single residue changes of L3733A and F3744A, within the FATC domain, resulted in transcriptional changes and phenotypes that were similar but not identical to those caused by mutations in the PI3K domain
\end{abstract}

Communicated by G. Braus.

Electronic supplementary material The online version of this article (doi:10.1007/s00294-010-0313-3) contains supplementary material, which is available to authorized users.

S. M. T. Hoke - A. Irina Mutiu - J. Genereaux - S. Kvas ·

G. B. Gloor · C. J. Brandl $(\bowtie)$

Department of Biochemistry,

Schulich School of Medicine and Dentistry,

University of Western Ontario, London N6A 5C1, Canada

e-mail: cbrandl@uwo.ca

M. Buck

Department of Biochemistry,

School of Medicine and Biomedical Sciences,

State University of New York, New York 14124, USA

M. Buck

Center of Excellence in Bioinformatics and Life Sciences,

Buffalo, NY 1420, USA

M. Yu

Department of Biological Sciences,

State University of New York, Buffalo, NY 14260, USA

Present Address:

A. Irina Mutiu

Southern Crop Protection and Food Research Centre,

Agriculture and Agri-Food Canada,

1391 Sandford St., London N5V 4T3, Canada or deletions of other SAGA or NuA4 components. The distinct nature of the FATC mutations was also apparent from the additive effect of tral-L3733A with SAGA, NuA4, and tral PI3K domain mutations. Tra1-L3733A associates with SAGA and NuA4 components and with the Gal4 activation domain, to the same extent as wild-type Tra1; however, steady-state levels of Tra1-L3733A were reduced. We suggest that decreased stability of Tra1-L3733A accounts for the phenotypes since intragenic suppressors of tralL3733A restored Tra1 levels, and reducing wild-type Tra1 led to comparable growth defects. Also supporting a key role for the FATC domain in the structure/function of Tra1, addition of a C-terminal glycine residue resulted in decreased association with Spt7 and Esa1, and loss of cellular viability. These findings demonstrate the regulatory potential of mechanisms targeting the FATC domains of PIKK proteins.

Keywords Gene expression - Tra1 · PIKK protein family . FATC domain $\cdot$ Yeast $\cdot$ SAGA complex

\section{Introduction}

Tra1 is a component of the yeast SAGA and NuA4 complexes, being the principal component that interacts with transcription activators (Bhaumik et al. 2004; Brown et al. 2001; Fishburn et al. 2005; Reeves and Hahn 2005). Tra1 is essential for viability in Saccharomyces cerevisiae (Saleh et al. 1998). Its mammalian homolog TRRAP is required for early embryonic development (Herceg et al. 2001) and the function of key cellular regulators such as c-Myc, p53, E2F1, $\beta$-catenin, and BRCA1 (reviewed by Murr et al. 2007). Tra1 and TRRAP are members of the phosphatidylinositol 3-kinase (PI3K) related kinase (PIKK) family, 
which also includes ATM, ATR, DNA-PKcs, TOR, and SMG-1. All of these molecules are important players in stress response, particularly related to DNA damage, cell growth, and proliferation (Abraham 2004). Tra1/TRRAP retains the PI3K domain, but the protein kinase activity demonstrated for many members of the family has not been found (McMahon et al. 1998; Saleh et al. 1998; Vassilev et al. 1998).

The SAGA complex is engaged in a number of nuclear processes. Its roles include facilitating recruitment of the transcriptional preinitiation complex (Bhaumik and Green 2001, 2002; Larschan and Winston 2005), promoting nucleosome eviction (Govind et al. 2007) and replicationcoupled nucleosome assembly (Burgess et al. 2010). These regulatory functions occur through the acetylation of nucleosomal histones H2B, H3, and Htz1 by the component protein Gen5 (Grant et al. 1997; Millar et al. 2006; RuizGarcia et al. 1997; Suka et al. 2001), the deubiquitylation of histone H2B by Ubp8 (Henry et al. 2003), and interaction with the basal transcriptional machinery (Dudley et al. 1999; Mohibullah and Hahn 2008; Saleh et al. 1997). The presence of the nuclear pore component Sus1 within SAGA also links the complex with mRNA export (Kohler et al. 2006, 2008).

The catalytic subunit of the NuA4 complex, Esa1, is essential for viability in $S$. cerevisiae and acetylates histones H2A, H4, and Htz1 (Allard et al. 1999; Millar et al. 2006). Acetylation by Esa1 is required for transcriptional regulation (Allard et al. 1999) and the DNA-damage response (Bird et al. 2002; Choy and Kron 2002; Downs et al. 2004). A subset of the other NuA4 component proteins, Eaf2, Act3/Arp4, Act1, and Yaf9, are shared with the Swr1 complex that introduces Htz1 into chromatin (Bird et al. 2002; Choy and Kron 2002; Downs et al. 2004; Krogan et al. 2003, 2004).

We previously characterized a class of tral alleles having mutations within the PI3K domain (Mutiu et al. 2007a). The most severe allele, tral-SRR3413 is a triple alanine scanning mutation that alters the serine-arginine-arginine residues found at positions 3413 to 3415 . The changes in gene expression in the tral-SRR3413 strain partially overlap those seen in strains with deletions of SAGA or NuA4 components and result in phenotypes consistent with the involvement of Tra1 in cell wall stability and stress response. Synthetic genetic array analysis identified genetic interactions of tral-SRR3413 with genes involved in gene expression, mitochondrial function, and membrane sorting/ protein trafficking (Hoke et al. 2008b). In addition, tralSRR3413 shows generation-dependent telomere shortening, a phenotype not seen with deletions of SAGA or NuA4 components (Mutiu et al. 2007a).

The extreme C-terminus of the PIKK proteins contains a 35-amino acid residue FATC domain (FRAP-ATM-
TRRAP C-terminus; Bosotti et al. 2000). For ATM, DNAPKcs, mTOR, and SMG-1, the FATC domain is necessary for the kinase activity of the adjacent PI3K domain (Beamish et al. 2000; Morita et al. 2007; Priestley et al. 1998; Sun et al. 2007; Takahashi et al. 2000). In addition, the FATC domain of ATM is required for interaction with Tip60, the mammalian homolog of Esa1 (Sun et al. 2005). ATR, TRRAP, and DNA-PKcs FATC domains can substitute for the native domain of ATM, restoring kinase activity and interaction with Tip60 (Jiang et al. 2006); however, functional equivalency across the family is not absolute since the ATM FATC domain cannot replace that of mTOR (Takahashi et al. 2000). A solution structure for the isolated FATC sequence of $S$. cerevisiae Tor 1 consists of an $\alpha$-helix with a C-terminal disulfide bonded loop (Dames et al. 2005). The generality of this structure is unclear given that the cysteine residues that form the disulfide bond are not present in other PIKK family members.

The goal of this study was to identify features of the FATC domain that are important for the function of the Tra1/TRRAP molecules. By analyzing mutations within the FATC domain of Tra1, we show that the FATC domain and precise positioning of the $\mathrm{C}$-terminal carboxyl group are required for function. Addition of a C-terminal glycine resulted in loss of viability and altered association with NuA4 and SAGA components. Alanine substitutions at L3733 or F3744 resulted in growth phenotypes and transcriptional changes related, but not identical, to those within the PI3K domain. Tra1-L3733A was characterized in more detail, as it caused the most specific growth defects. We suggest that the functional changes of Tra1L3733A are due to a role for the FATC domain in maintaining a stable form of the protein since the steady state level of Tra1-L3733A was $25 \%$ of that seen for wild-type Tra1, and suppressor mutations that partially restored function of Tra1-L3733A increased its concentration to a similar extent. These findings demonstrate the importance of the FATC domain in the structure/function of Tra1 and emphasize the pronounced consequences of any regulatory mechanism that targets the FATC domain of the Tra1/TRRAP proteins.

\section{Materials and methods}

Yeast strains and growth

Yeast strains are listed in Table 1. CY4060 is a derivative of BY4743 in which one copy of TRAl has been gene replaced with tral-L3733A that contains a HIS3 allele at the downstream BstBI site. CY4060 was sporulated to generate MATa and MAT $\alpha$ haploid strains (CY4103 and CY4057, respectively) that were then crossed to deletion derivatives 
Table 1 Strains used in this study

\begin{tabular}{|c|c|c|c|}
\hline Strain & Genotype & TRA1 plasmid(s) & Reference \\
\hline KY320 & 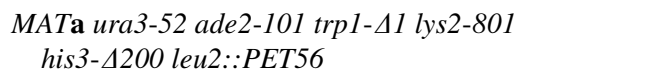 & & Chen and Struhl (1988) \\
\hline CY1021 & Isogenic to KY320 except tra1::Tn10LUK & myc-TRA1 & Saleh et al. (1998) \\
\hline CY2706 & Isogenic to CY1021 & $m y c_{9}-T R A 1$ & This work \\
\hline CY2707 & Isogenic to CY 1021 & $m y c_{9}$-tral-L3721D & This work \\
\hline CY3003 & Isogenic to CY 1021 & $m y c_{9}$-tral-L3733A & This work \\
\hline CY3019 & Isogenic to CY1021 & myc-TRA1 myc $c_{9}$-tral-G3745 & This work \\
\hline CY3020 & Isogenic to CY1021 & myc-TRA1 myc $c_{9}-T R A 1$ & This work \\
\hline CY3083 & Isogenic to CY 1021 & $T A P-F L A G-T R A 1$ & This work \\
\hline CY3084 & Isogenic to CY1021 & TAP-FLAG-tral-L3721D & This work \\
\hline CY3085 & Isogenic to CY 1021 & TAP-FLAG-tral-L3733A & This work \\
\hline CY4055 & Isogenic to CY1021 & $m y c_{9}$-tral-L3733A/N3677D & This work \\
\hline CY4056 & Isogenic to CY1021 &  & This work \\
\hline BY4743 & $\begin{array}{l}\text { MATa/ } \alpha \text { his } 3 \Delta 1 / \text { his } 3 \Delta 1 \text { leu } 2 \Delta 0 / \text { leu } 2 \Delta 0 \text { LYS2/ } \\
\text { lys } 2 \Delta 0 \text { met15 } \triangle 0 / \text { MET15 ura } 3 \Delta 0 / \text { ura } 3 \Delta 0\end{array}$ & & Winzeler and Davis (1997) \\
\hline BY4741 & MATa ura3 $\Delta 0$ met $15 \Delta 0$ his $3 \Delta 0$ leu $2 \Delta O$ & & Winzeler and Davis (1997) \\
\hline BY4742 & MAT $\alpha$ ura $3 \Delta 0$ lys $2 \Delta 0$ his $3 \Delta 0$ leu $2 \Delta 0$ & & Winzeler and Davis (1997) \\
\hline TAP-ADA2 & Isogenic to BY4741 except TAP-ADA2-HIS3 & & Ghaemmaghami et al. (2003) \\
\hline CY2998 & Isogenic to TAP-ADA 2 except $\operatorname{trp} 1:: U R A 3$ & & This work \\
\hline TAP-SPT7 & Isogenic to BY4741 except TAP-SPT7-HIS3 & & Ghaemmaghami et al. (2003) \\
\hline CY3001 & Isogenic to TAP-SPT7 except $\operatorname{trp} 1: \because U R A 3$ & & This work \\
\hline TAP-ESA1 & Isogenic to BY4741 except TAP-ESA1-HIS3 & & Ghaemmaghami et al. (2003) \\
\hline CY3002 & Isogenic to TAP-ESA1 except $\operatorname{trp} 1: \because U R A 3$ & & This work \\
\hline CY1524 & Isogenic to CY1021 & Flag $_{3}-T R A 1_{S B}$ & Mutiu et al. (2007a) \\
\hline CY1531 & Isogenic to CY 1021 & Flag $_{3}-T R A 1-S R R 3413$ & Mutiu et al. (2007a) \\
\hline BY7240 & Isogenic to BY4741 except yaf $9:: K a n^{r}$ & & Winzeler and Davis (1997) \\
\hline CY4060 & Isogenic to BY4743 except TRAl/tral-L3733A-HIS3 & & This work \\
\hline CY4057 & MAT $\alpha$ ura3 40 his3 40 leu $2 \Delta 0$ tral-L3733A-HIS3 & & This work \\
\hline CY4103 & MATa ura3 $\triangle 0$ his $3 \Delta 0$ leu $2 \Delta 0$ tral-L3733A-HIS3 & & This work \\
\hline CY4318 & MAT $\alpha$ ura $3 \Delta 0$ his $3 \Delta 0$ leu $2 \Delta 0$ tral-A3727S-HIS3 & & This work \\
\hline CY4324 & MATa ura $3 \Delta 0$ his $3 \Delta 0$ leu $2 \Delta 0$ tral-F3740A-HIS3 & & This work \\
\hline CY4350 & MATa ura3 $\Delta 0$ his $3 \Delta 0$ leu $2 \Delta 0$ tral-F3744A-HIS3 & & This work \\
\hline CY4353 & MATa ura3 $\triangle 0$ his3 30 leu $2 \Delta 0$ TRA1-HIS3 & & This work \\
\hline FY630 & MAT $\alpha$ his4-917 lys2-173 R2 leu2 & & Gansheroff et al. (1995) \\
\hline FY1093 & Isogenic to FY630 except spt7::LEU2 & & Gansheroff et al. (1995) \\
\hline QY204 & MATa his3 4200 trp1 $\triangle 63$ ura3-52 leu2 $\Delta 1$ lys $2-128 \Delta$ & & Nourani et al. (2004) \\
\hline QY202 & Isogenic to QY204 except yng2::Kan ${ }^{r}$ & & Nourani et al. (2004) \\
\hline
\end{tabular}

of BY4741 and BY4742 and sporulated to analyze the double mutant strains. CY4353, CY4318, CY4324, and CY4350 are similarly engineered strains containing wildtype TRA1, tral-A3734S, tral-F3740A, and tral-F3744A.

TRA1 alleles contained on TRPI centromeric plasmids were transformed into CY1021 (Saleh et al. 1998) and the wild-type copy on a URA3-centromeric plasmid displaced by plasmid shuffling. Growth comparisons were performed on plates at $30^{\circ}$ unless stated otherwise. Assays were performed in duplicate on independently constructed strains. Scoring of
FATC domain mutations was relative to CY2706, which contains $T R A 1_{W T}$, the background allele used to construct the mutations. $T R A 1_{W T}$ is N-terminally myc $_{9}$-tagged and contains a BamHI site that converts N3580A.

TAP-tagged ADA2 (YSC1178-7500046), SPT7 (YSC1178-7499287) and ESA1 (YSC1178-7502907) (Ghaemmaghami et al. 2003) BY4741, and BY7042 (yaf9::Kan ${ }^{r}$ ) were purchased from Open Biosystems. These strains were made trp $1:: U R A 3$ and leu2::HIS3 using pTU10 and pLH7, respectively (Cross 1997). 
Table 2 Oligonucleotides used in this study a TRA1 sequence that enables the PCR and cloning of an internal restriction fragment

\begin{tabular}{|c|c|c|}
\hline Name & Sequence $\left(5^{\prime}-3^{\prime}\right)$ & Description \\
\hline 2346 & ATACGAGCTCTTTGAGGCTTTCTCTACCTTC & Outside end of $T R A l^{\mathrm{a}}$ \\
\hline $2323-2$ & TCGGGATCCGCATGGGCCCAATGGGGTTT & \\
\hline $4249-3$ & GCGGCCGCAAACGCAGCGCATGATGATG & \\
\hline $2583-1$ & CGGGATCCGTATTTACTTTAGAAATGTTAC & BamHI/TRA1 \\
\hline $2583-2$ & GAGGATCCAGAGGTTTTGTCAACATGG & \\
\hline $5138-3$ & TCATCCTAGCCTGTATTGGCAGCGCTG & L3721D \\
\hline $5138-4$ & GCCAATACAGGCTAGGATGAACTGGGTTG & \\
\hline $5138-1$ & CAGTTCATCGATGACTGTATTGGCAGCGC & D3722A \\
\hline $5138-2$ & CAATACAGTCATCGATGAACTGGGTTGTGAC & \\
\hline \multirow[t]{3}{*}{ 55-IDT } & GCTCTAGAACCATGGCATGAAGTTGACGTCTGT & A3727S \\
\hline & TCTTGCTAAGTTTCTTGGACTGACAGAGCTGCC & \\
\hline & AATACAGTCTAGG & \\
\hline $5185-1$ & TCTGTTCTTGCTGCGTTTCTTGGACTGACAGCG & L3733A \\
\hline $5185-1$ & TCCAAGAAACGCAGCAAGAACAGACGTGAAC & \\
\hline $5138-5$ & TAGCAAGAACATACGTGAACTTCATGCCA & D3737Y \\
\hline $5138-6$ & AAGTTCACGTATGTTCTTGCTAAGTTTCTT & \\
\hline $5714-1$ & GAACCATGGCATGGCGTTCACGTCTGTTCTTGC & F3740A \\
\hline $5747-1$ & CCCGAGCTCTTGATTGTTAGCAATACCG & F3744A \\
\hline $5747-2$ & CATGCCATGGGCCTAGAGCTGATACATGGGGT & \\
\hline $5164-1$ & ATACGAGCTCCTACCCGAACCATG & G3745 \\
\hline $5088-1$ & GGCCGATGAACAAAAATTGATTTCTGA & $m y c$-tag \\
\hline $5088-2$ & GGCCGCCAAATCTTCTTCAGAAATCAA & \\
\hline $5295-1$ & AACTGCAGTTTAGTACTAACAGAGACTTTTG & MET3 promoter \\
\hline $5295-2$ & CCCAAGCTTAATTATACTTTATTCTTGTTATTAT & \\
\hline $3203-1$ & CGGGATGGTTAAGAGGCCAACGTCGATG & $R P L 35 a$ promoter \\
\hline $3203-3$ & CCAATTGAGAAGCCAATTGTTC & \\
\hline $5669-1$ & AATTGAAGGGGCGGAATTCAGGGGCGGAG & STRE \\
\hline $5669-2$ & CCGCCCTGAATTCCGCCCCTTC & \\
\hline $5583-1$ & GTATCGATTCATTTAGACATTGC & PHO5 CHIP \\
\hline $5583-2$ & ATCCGAAAGTTGTATTCACCAAG & \\
\hline $5526-1$ & $\begin{array}{l}\text { GCTGGTAAATTCAACGAGGCGGATAATTCCTTAA } \\
\text { CCAGGGGCCA }\end{array}$ & $A D E 17$ \\
\hline $5526-2$ & $\begin{array}{l}\text { GGAACCCCAGACTTGGTCCAACTTGGTGAAAGCA } \\
\text { GCTTCGGTCC }\end{array}$ & $R P L 4 b$ \\
\hline
\end{tabular}

DNA constructs

The PHO5-LacZ reporter constructs in the LEU2 centromeric plasmid YCp87 were described previously (Mutiu et al. 2007b). Rpl35a-LacZ was similarly constructed using the oligonucleotides indicated in Table 2. A HIS3-LacZ fusion regulated by two STRE elements (SRE/his3-LacZ) in place of the Gcn4 binding site was constructed by annealing oligonucleotides 5669-1 and 5669-2 and inserting the fragment into the EcoRI and SacI sites of his3-488-LacZ (Brandl et al. 1993).

$m y c_{9}$-TRA1-YCplac111 was constructed through consecutive ligation of oligonucleotides 5088-1 and 5088-2 (see Table 2) into myc-TRA1-YCplac111 (Saleh et al. 1998). A BamHI site at position 10734 of TRAl was introduced by two-step PCR using oligonucleotide pairs of 2583-1 with 2346 and 2583-2 with 2323-2 and cloned as an ApaI-SacI restriction fragment into full-length TRAl to give $m y c_{9^{-}}$ TRA $1_{W T}$. Mutations of L3721D, D3722A, L3733A, D3737Y, and G3745 were similarly engineered. Initial reactions contained a listed oligonucleotide and the appropriate outside flanking primer with a unique cloning site (oligonucleotides 2346 and 4249-3). Fragments were moved into $m y c_{9}-T R A 1_{W T}$-YCplacl11 using BamHI-SacI restriction sites. T3714I and I3720D were serendipitously isolated in sequencing of random alleles.

To integrate tral-A3727S, L3733A, F3740A, and $F 3744 A$ into the genome, mutations were introduced into the 3' SphI-FspI fragment of the gene and flanking region using the oligonucleotides listed in Table 2 and the terminal 
NcoI site for cloning. The DNA contained HIS3 at the $B s t \mathrm{BI}$ site to allow selection in yeast. A plasmid copy of YHR100C was transformed into the strains to ensure that this gene was not affected by the integration.

A 495-bp fragment of the MET3 promoter flanked by PstI and NotI sites was cloned into the molecules expressing TRA1 after PCR with oligonucleotides 5295-1 and 5295-2. TAP-tagged TRA1 molecules were cloned into a LEU2 derivative of the YCpDed-TAP construct described previously (Mutiu et al. 2007a).

\section{$\beta$-Galactosidase assays}

Yeast strains containing RPL35a-LacZ were grown in YPD to an $A_{600}$ of $\sim 1.5$, pelleted, washed in LacZ buffer, and concentrated fivefold. $\beta$-Galactosidase was determined using $o$-nitrophenol- $\beta$-D-galactosidase as substrate, standardizing to cell density (Ausubel et al. 1988). For analysis of PHO5-LacZ under inducing conditions, overnight cultures were washed three-times in water then grown $15 \mathrm{~h}$ in YPD depleted of phosphate (Han and Grunstein 1988). STRE/his3-LacZ and his3-488-LacZ were assayed after growing tenfold dilutions of saturated cultures (from minimal media) for $15 \mathrm{~h}$ in YPD containing 4\% ethanol.

RNA purification and gene profiling

Yeast cells, CY2706, and CY3003, were grown at $30^{\circ}$ in YP media containing $2 \%$ glucose to an $A_{600}=2.0$. RNA was purified from $10^{8}$ cells after glass bead disruption as described previously (Mutiu and Brandl 2005). RNA integrity numbers of greater than 8.9 were determined for each RNA sample using an Agilent 2100 Bioanalyzer at the London Regional Genomics Centre. mRNA-Seq libraries were constructed and sequencing were performed on the Illumina/Solexa Genome Analyzer II platform at the DNA Facility at Iowa State University. The CY2706 and CY3003 samples were each run on a single Illumina GAII lane, producing 13014880 reads for CY2706 and 11156078 reads for CY3003 of 35 nucleotides. The $S$. cerevisiae genome sequence and the general features format file (saccharomyces_cerevisiae.gff) were obtained from Saccharomyces Genome Database on May 1, 2009. The sequencing reads were mapped onto the genomic sequence using the novoindex and novoalign programs with the default parameters, except that reads mapping to two or more places in the genome were placed at one position at random. With this option novoalign marks a read as uniquely or repetitively mapping in the genome; only uniquely mapping reads were used for the subsequent analysis (83 and 84\% for CY2706 and CY3003, respectively). Mapped reads were placed into bins composed of protein-coding genes, tRNA and rRNA genes as defined by the gff file. Only reads that did not overlap the start or end position of the gene were counted and reads mapping to the top and bottom strands were tabulated separately. The relative occurrence of each ORF annotated in the Saccharomyces Genome Database as a ratio of its length was calculated after normalization to 10 million reads for each sample, similar to the normalization outlined in Mortazavi et al. (2008). Genes with $\geq 0.05$ reads per base pair of gene length were considered for further analysis. Agglomerative hierarchical clustering based on the average linkage of uncentered correlations was performed using CLUSTER 3.0 software (Eisen et al. 1998) on the profiles from strains within the compendium data set (Hughes et al. 2000) the data sets of strains containing deletions of NuA4 (Krogan et al. 2004) and SAGA components (Ingvarsdottir et al. 2005) and with tral-SRR3413 (Mutiu et al. 2007a). Genes not appearing in at least two of the profiles were excluded. The data were visualized using MAPLETREE (http://rana.lbl.gov/EisenSoftware.htm).

RNA dot blots with probes for ADE17 and RPLAa/b (Table 2) were performed on Hybond-N membrane (Amersham) using 10 and $2.5 \mu \mathrm{g}$ of total RNA, essentially as described by the manufacturer. Hybridizations were performed in buffer containing $5 \times$ standard saline citrate (SSC), $5 \times$ Denhardt's solution, $0.5 \%$ sodium dodecyl sulphate (SDS), and $90 \mu \mathrm{g} / \mathrm{ml}$ denatured herring sperm DNA at $52^{\circ}$. Washes in $2 \times$ SSC plus $0.1 \%$ SDS and $1 \times$ SSC plus $0.1 \%$ SDS were performed at $42^{\circ}$.

Chromatin immunoprecipitation assays

Assays for acetylated histones were performed essentially as described previously (Hoke et al. 2008a). Cells were grown in YPD media to an $A_{600} \sim 2.0$. Antibodies were purchased from Abcam Inc. (anti-H3, ab1791; anti-AcH4/ K8, ab1760).

\section{Western blotting}

Yeast extract prepared by grinding in liquid nitrogen or by lysis with glass beads (Saleh et al. 1997) was separated by SDS-PAGE and transferred to PVDF membrane (Roche Applied Science). Anti-myc (Evan et al. 1985), anti-Mcm2 (Santa Cruz Biotechnology, Cat. \# sc-6680; kindly supplied by Megan Davey), and anti-calmodulin-binding protein (CBP) antibodies (Millipore Corp., Cat. \# 07-482) were used at ratios of 1:5000, 1:4000, and 1:1000, respectively. Secondary antibody (anti-Mouse IgG HRP, Promega; antiGoat IgG HRP, Sigma; anti-Rabbit IgG HRP, Promega) used at a ratio of 1:10000 was detected using SuperSignal West Pico Chemiluminiscent Substrate (Thermo Scientific). Densitometric scanning of films was performed using AlphaImager 3400 software (Alpha Innotech, Inc.). 
TAP purification

Whole cell extracts were prepared by grinding in liquid nitrogen (Saleh et al. 1997). Tandem affinity purification (Rigaut et al. 1999) with 11 of extract grown in minimal media lacking tryptophan to an $A_{600} \sim 2$ was carried out as described previously (Mutiu et al. 2007a).

Genome-wide localization studies

Genome-wide localization studies were performed essentially as described (Yu et al. 2004) for yeast strain CY2706 grown at $30^{\circ}$ in YPD. Immunoprecipitations were performed in triplicate with $10 \mu \mathrm{l}$ of anti-myc antibody (9E11) and using pan-mouse IgG Dynal beads (Invitrogen). Antibody was pre-incubated with the beads in $1 \times$ phosphatebuffered saline containing $5 \mathrm{mg} / \mathrm{ml}$ BSA for a minimum of $2 \mathrm{~h} . P$ values were calculated using an error model provided by Rosetta Resolver. The genome-wide occupancy was expressed as the ratio of fluorophore intensities from chromatin fragments enriched by immunoprecipitation versus that of the input chromatin fragments. Spots with a $P$ value threshold of 0.02 and a ratio of intensity $>1.0$ were included in the final dataset (Online Resource 1).

\section{Isolation of intragenic suppressors of tral-L3733A}

C-terminal sequences of tral-L3733A downstream of the $A p a \mathrm{I}$ site at base pair 9175 were mutagenized by PCR, cloned back into the full-length molecule, and shuffled into yeast strain CY4018 by selection on 5-FOA. Individual colonies were selected for growth on YPD plates containing $4 \%$ ethanol; the plasmids were isolated, sequenced, and verified for plasmid dependency of the selection by repeating the selection process after transformation into CY1021.

\section{Gal4 affinity chromatography}

Interaction of myc $_{9}$-Tra1 constructs from yeast strain CY2998 with recombinant activation domain of Gal4 was performed as described by Mutiu et al. (2007a).

\section{Results}

Characterization of mutations within the FATC domain of Tra1

The C-terminal region of the Tra1/TRRAP family contains three conserved domains: FAT (FRAP-ATM-TRRAP), phosphatidylinositol 3-kinase-like (PI3K) and FATC (FAT C-terminal; Fig. 1a). To identify key residues required for function, we introduced mutations into the FATC domain.
To identify residues to target, we analyzed an alignment of the FATC domains of Tra1/TRRAP from five species (Fig. 1b, upper alignment) and an alignment of S. cerevisiae Tra1 with the FATC domains from members of the PIKK family (lower alignment). L3733 and A3727 (numbering for S. cerevisiae Tra1) are highly conserved throughout the PIKK family, as are hydrophobic residues at positions equivalent to I3720, I3724, F3740, W3743, and F3744. An acidic residue is conserved at D3737 within Tra1/TRRAP, but is aromatic in the broader family. Other positions are conserved in the fungal forms of Tra1. We constructed alleles of $S$. cerevisiae TRA1 with changes to these different classes of residues (see Fig. 1b). The L3733A change was of particular interest because the comparable mutation in SMG-1 results in loss of kinase activity (Morita et al. 2007). Some of the changes, for example, L3721D and D3737Y, were made to resemble the residues found in the PIKK family. Another allele, which we have termed tral-G3745, was constructed with a glycine codon following the terminal phenylalanine codon to analyze the importance of the positioning of the terminal carboxyl group.

The initial tral alleles analyzed (T3714I, I3730D, L3721D, D3722A, L3733A, D3737Y and G3745) were introduced on TRPl-centromeric plasmids into S. cerevisiae strain CY1021, which contains a disruption of the genomic copy of TRAl, complemented by wild-type TRAI expressed from a $U R A 3$-containing centromeric plasmid. Interestingly, tral-G3745 and to a lesser extent tral$L 3733 A$, resulted in slow growth in combination with the wild-type allele (not shown). The alleles were examined for their ability to support viability by shuffling out wild-type TRA1 on media containing 5-fluoroorotic acid. The six alleles with single residue changes supported growth, whereas tral-G3745 did not. Of the viable strains, only the strain containing tral-L3733A had obvious growth defects.

The tral-L3733A allele resulted in several phenotypes shared with strains having mutations in the ada genes (Fig. 1c; Table 3). These phenotypes included slow growth on media containing ethanol, Calcofluor white, or tunicamycin. Interestingly, however, it did not display the classic ada phenotype of resistance to overexpression of VP16 (Berger et al. 1992). The tral-L3733A allele decreased growth on media containing tert-butylhydroperoxide, or lacking inositol, both characteristics of defects in Spt function (Gansheroff et al. 1995). A dichotomy was seen for NuA4-related phenotypes, as the tral-L3733A strain was sensitive to benomyl but not methylmethane sulphonate.

The phenotypes of the tral-L3733A strain were similar but not identical to those of the tral-SRR3413 strain (Mutiu et al. 2007a). Similarities included slow-growth on media containing ethanol, Calcofluor white, benomyl, rapamycin, geneticin, and chloramphenicol; whereas, differences in 
A

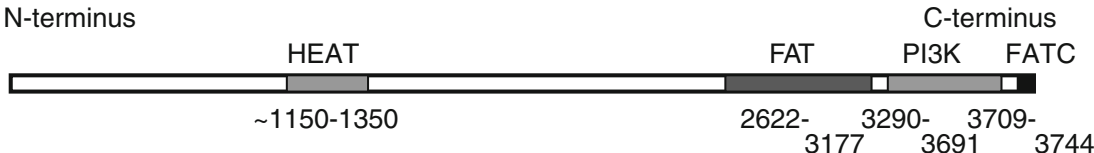

B

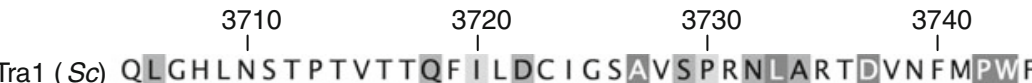

Tra2 ( $S p)$ VI SHNVPEDLPLNQTLVDLVSQATNPQQLAQMDQLWQAWL

Tra1 (Sp) SLSQVAYGNLPVNQTA I DYLAQAS S S KVLAQMDVLWAPWL

Tra1 (NC) SLAQAPAGNLPAYQT I I DL I AKAVSPLNLAQCEALWMPYL

Nipped-A $(D m)$ K I SYFDS I - - ENKK I S VLVQSATN I DN LCRMDPAWHPWL

$\operatorname{TRRAP}(H s)$ NLAQF EGG - - - ESK - VNT LVAAANSL DNLCRMDPAWHPWL

Tra1/

TRRAP

I DDA $s$ A Y a a

$\operatorname{Tra1}(S c)$ QLGHLNSTPTVTTQF I LDCIGSAVS PRNLARTDVNFMPWF
$\operatorname{TRRAP}(H s)$ TRLHNLAQFEGGESKVNTLVAAANSLDNLCRMDPAWHPWL

$\operatorname{ATM}(H s)$ G - - VE EGTVL S VGGQVNL L I QQA I D P KNLSR L F PGWKAWV

ATR $(H s)$ TRNRVTGLPLS I EGHVHYL I QEATDEN L LCQMYLGWTPYM PIKK

DNA-PKcs $(H s)$ I RAQE P E SG LSE ETQVKCLMDQATDPN I LGR TWE GWE PWM

Tor1 (SC) GND I KR FNE LDVPEQVDKL I QQATS I ERLCQHY I GWCPFW

SMG1 $(H s)$ GRDVDPNRRMSVAEQVDYVIKEATNLDNLAQLYEGWTAWV

c

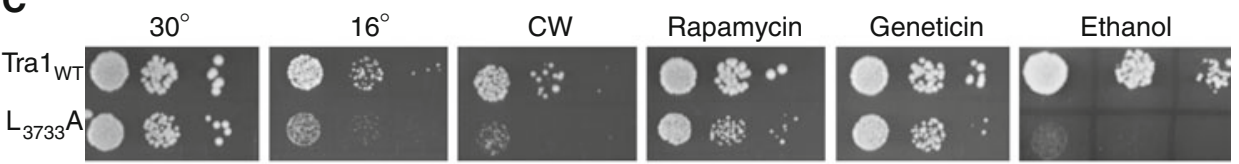

D

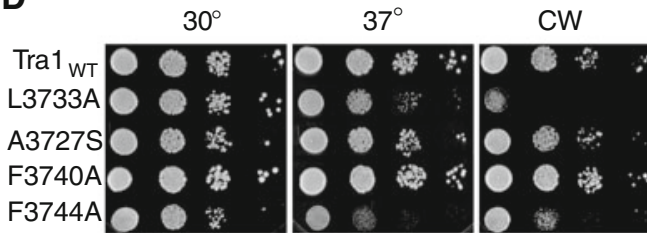

Rapamycin

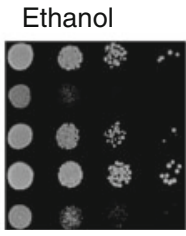

Fig. 1 FATC domain mutants. a Schematic diagram of the architecture of the Tra1/TRRAP family indicating the approximate positions of the HEAT, FAT, PI3 K, and FATC domains (Bosotti et al. 2000; Murr et al. 2007). Numbering is for the 3744 residues of $S$. cerevisiae Tra1. b Sequence alignment of FATC domains from PIKK family proteins. Top panel Sequences are Saccharomyces cerevisiae Tra1 (NP_011967), Schizosaccharomyces pombe Tra2 (Q10064), Schizosaccharomyces pombe Tra1 (NP_595777), Neurospora crassa Tra1 (CAC18279), Drosophila melanogaster Nipped-A (NP_001097192), Homo sapiens TRRAP (NP_003487). Lower panel Sequences from Saccharomyces cerevisiae Tra1 (NP_011967), Tor1 (CAA52849) and Homo sapiens TRRAP (NP_003487), ATM (Q13315), ATR (Q13535), DNA-PKcs (P78527) and SMG-1 (NP_055907). Residues indicated between the alignments in bold capitals are those changes that were analyzed through plasmid shuffling. Lower case letters indicate residues analyzed by gene integration, see c. Numbering is for

sensitivity to tert-butylhydroperoxide and tunicamycin were observed. In addition, defects in telomere maintenance or elongation were not observed using the plasmid linearization assay of Lundblad and Szostak (1989; not shown).

To examine the importance of the highly conserved alanine at 3727 and the hydrophobic residues, F3740 and F3744, we constructed yeast strains in which tral-A3727S, tral-F3740A, tral-F3744A, as well as tral-L3733A were integrated into the genome of the wild-type strain BY4741/
S. cerevisiae Tra1. Alignments were performed using the default parameters of the ClustalW utility [http://www.ebi.ac.uk/clustalw/] and the terminal 49 residues of each protein. $\mathbf{c}$ Growth of the tral$L 3733 A$ strain. Yeast strains containing centromeric plasmids expressing tral-L3733A and $T R A 1_{W T}$ were grown to saturation and ten-fold serial dilutions plated onto YP media containing $2 \%$ glucose and grown at $30^{\circ}$ or $16^{\circ}$, or at $30^{\circ}$ on YPD containing $5 \mu \mathrm{g} / \mathrm{ml}$ Calcofluor white (CW), $1 \mathrm{nM}$ rapamycin, $20 \mu \mathrm{g} / \mathrm{ml}$ geneticin, or $4 \%$ ethanol. d Analysis of integrated tral alleles. TRA1 $1_{W T}$, tral-L3733A, tral-A2727S, tralF3740A and tral-F3744A were integrated into BY4743. Haploids containing the integrated allele were obtained after sporulation. Saturated cultures were serially diluted and plated onto YPD at $30^{\circ}$ or $37^{\circ}$, or at $30^{\circ}$ on YPD containing $5 \mu \mathrm{g} / \mathrm{ml}$ Calcofluor white (CW), $1 \mathrm{nM}$ rapamycin, or $6 \%$ ethanol. We note that the BY4742/4741 background is less sensitive to ethanol than KY320, so ethanol sensitivity was assayed at a concentration of $6 \%$

4742 and analyzed growth under a variety of conditions (Fig. 1d). Similar to the plasmid copy, the integrated allele of tral-L3733A, expressed from its native promoter, resulted in slow growth at $37^{\circ}$ and in media containing Calcofluor white, rapamycin, and ethanol. The tral-A3727S strain was slightly sensitive to each of these conditions; in comparison, the tral-F3740A strain was relatively unaffected. Mutation of the terminal phenylalanine to alanine $(\mathrm{F} 3744 \mathrm{~A})$ resulted in a general reduction in viability in all conditions assayed, including rich media at $30^{\circ}$. This 
Table 3 Phenotypes of tral-L3733A and tral-SRR3413 strains

\begin{tabular}{|c|c|c|c|c|c|c|}
\hline Condition $^{\mathrm{a}}$ & tral-L3733A & tral-SRR ${ }^{\mathrm{c}}$ & $a d a 2 \Delta 0$ & $\operatorname{spt7} \Delta 0$ & $y n g 2 \Delta 0$ & yaf9 90 \\
\hline Ethanol & $\mathbf{S}^{\mathrm{d}, \mathrm{e}}$ & $\mathrm{S}$ & $\mathbf{S}$ & $\mathbf{S}$ & $\mathrm{N}$ & $\mathrm{N}$ \\
\hline Calcofluor white & $\mathbf{S}$ & $\mathrm{S}$ & $\mathbf{S}$ & $\mathbf{S}$ & $\mathrm{s}$ & $\mathrm{N}$ \\
\hline Tunicamycin & $\mathbf{S}$ & $\mathrm{N}$ & $\mathbf{S}$ & $\mathrm{s}$ & $\mathrm{N}$ & $\mathrm{N}$ \\
\hline Overexpression of VP16 & $\mathrm{N}$ & $\mathrm{N}$ & $\mathrm{R}$ & $\mathrm{N}$ & $\mathrm{N}$ & $\mathrm{S}$ \\
\hline tert-Butylhydroperoxide & $\mathbf{S}$ & $\mathrm{N}$ & $\mathrm{N}$ & $\mathbf{S}$ & $\mathrm{N}$ & $\mathrm{N}$ \\
\hline Depleted of inositol & $\mathrm{s}$ & $\mathrm{S}$ & $\mathrm{N}$ & $\mathrm{S}$ & nd & nd \\
\hline Benomyl & $\mathbf{S}$ & $\mathrm{S}$ & $\mathrm{N}$ & $\mathrm{N}$ & $\mathbf{S}$ & $\mathbf{S}^{\mathrm{f}}$ \\
\hline Methylmethane sulphonate & $\mathrm{N}$ & $\mathrm{s}$ & $\mathrm{N}$ & $\mathrm{N}$ & $\mathrm{S}$ & $\mathrm{N}$ \\
\hline Rapamycin & $\mathbf{S}$ & $S$ & $\mathrm{~N}$ & nd & $\mathbf{S}$ & $\mathbf{S}$ \\
\hline Geneticin & $\mathrm{S}$ & $\mathrm{S}$ & $\mathrm{N}$ & $\mathrm{N}$ & $\mathrm{N}$ & $\mathrm{s}$ \\
\hline Chloramphenicol & $\mathrm{S}$ & $\mathrm{S}$ & $\mathrm{N}$ & $\mathrm{s}$ & $\mathrm{N}$ & nd \\
\hline
\end{tabular}

${ }^{a}$ Growth was assessed at $30^{\circ} \mathrm{C}$ on YPD media containing $4 \%$ ethanol, $5 \mu \mathrm{g} / \mathrm{ml}$ Calcofluor white, $1.5 \mu \mathrm{g} / \mathrm{ml}$ tunicamycin, $1.0 \mathrm{nM}$ rapamycin, $0.015 \%$ tert-butylhydroperoxide, $20 \mu \mathrm{g} / \mathrm{ml}$ benomyl, $0.025 \%$ methylmethane sulphonate, $20 \mu \mathrm{g} / \mathrm{ml}$ geneticin, or $0.6 \mu \mathrm{g} / \mathrm{ml} \mathrm{chloramphenicol}$

b Yeast strains (and their relevant controls) are the following: tral-L3733A, CY3003 (CY2706); tral-SRR, CY1531 (CY1524); ada2 A0, CY947 (KY320); spt 40 , FY1093 (FY630); yng2 40, QY202 (QY204); yaf9 40, BY7240 (BY4741)

c tral-SRR3413, see Mutiu et al. (2007b)

${ }^{\mathrm{d}} S$ slow growth as compared with wild-type, $s$ partial slow growth, $N$ same sensitivity as wild-type, $R$ resistant, $n d$ not determined

e Phenotypes of tral-L3733A shared with ada2 $\Delta 0$, spt7 $\Delta 0$, yng $2 \Delta 0$, or yaf $9 \Delta 0$ are in bold

${ }^{\mathrm{f}}$ Le Masson et al. (2003)

reduced viability demonstrates the importance of the terminal residue for Tra1 function and is consistent with the inability of tral-G3745 to support viability. Interestingly, tral-F3744A did not result in as pronounced specific phenotypes as seen with tral-L3733A. In fact, the tral-F3744A strain was slightly less sensitive to Calcofluor white and ethanol than the tral-L3733A strain.

Transcriptional effects of mutations within the FATC domain

The effects of the FATC domain mutations on transcription were initially assayed by determining the expression of the SAGA and NuA4-dependent PHO5 promoter (Barbaric et al. 2003; Nourani et al. 2004). LacZ assays were performed under inducing conditions with the integrated tral alleles (wild-type, L3733A, A3727S, F3740A and F3744A; Fig. 2a). The effect of these alleles on PHO5 expression followed a similar pattern to their effects on growth. Tra1L3733A and F3744A reduced PHO5 expression to $\sim 20 \%$ of wild-type. Tra1-A3727S and F3740A had a more modest effect, reducing expression to $\sim 60 \%$ of wild-type. We note that this compares with $\mathrm{PHO}-\mathrm{LacZ}$ expression of $<5 \%$ of the wild-type level seen upon deletion of either the SAGA component, Spt7 or NuA4 component, Yng2 (not shown).

The phenotypes of the tral-L3733A strain suggested a partial inability to respond to environmental change and stress. Though multiple factors are involved in the cellular response to stress, a general stress response involves tran- scriptional induction upon binding of transcription factors Msn2 and Msn4 to stress response elements (STRE elements) (Gasch et al. 2000; Harbison et al. 2004; MartinezPastor et al. 1996). To determine if tral-L3733A affected activation through STRE elements, we constructed a hybrid promoter containing two STRE elements at the position of the Gcn4-binding site in the HIS3 promoter, and assayed transcription when cells were grown in YPD containing 4\% ethanol. As shown in Fig. 2b, expression of STRE/his3 was reduced threefold in the tral-L3733A strain. The effect of the L3733A mutation was dependent on the stress response elements as the comparable promoter lacking the STRE elements (his3-488) was only slightly affected.

To analyze for transcriptional effects of the tral-L3733A allele on a broader scale, we compared the gene expression profiles of wild-type (CY2706) and tral-L3733A (CY3003) strains grown in YPD using next generation sequencing. The full data set has been submitted to the Gene Expression Omnibus at the National Center for Biotechnology: accession number GSE18591. After normalization, expression of 11 genes was elevated $\geq 2$-fold; 79 genes were decreased $\geq 2$-fold (Table 4). While no over-riding patterns were apparent, of the 11 genes with elevated expression, HSP26, PIR3, DDR2, and GRE1 have roles in the cellular response to stress. Confirmation of the general profile seen by sequencing was obtained by the analysis of LacZ-reporter fusions and dot blotting for selected genes as shown in Fig. 2c. 

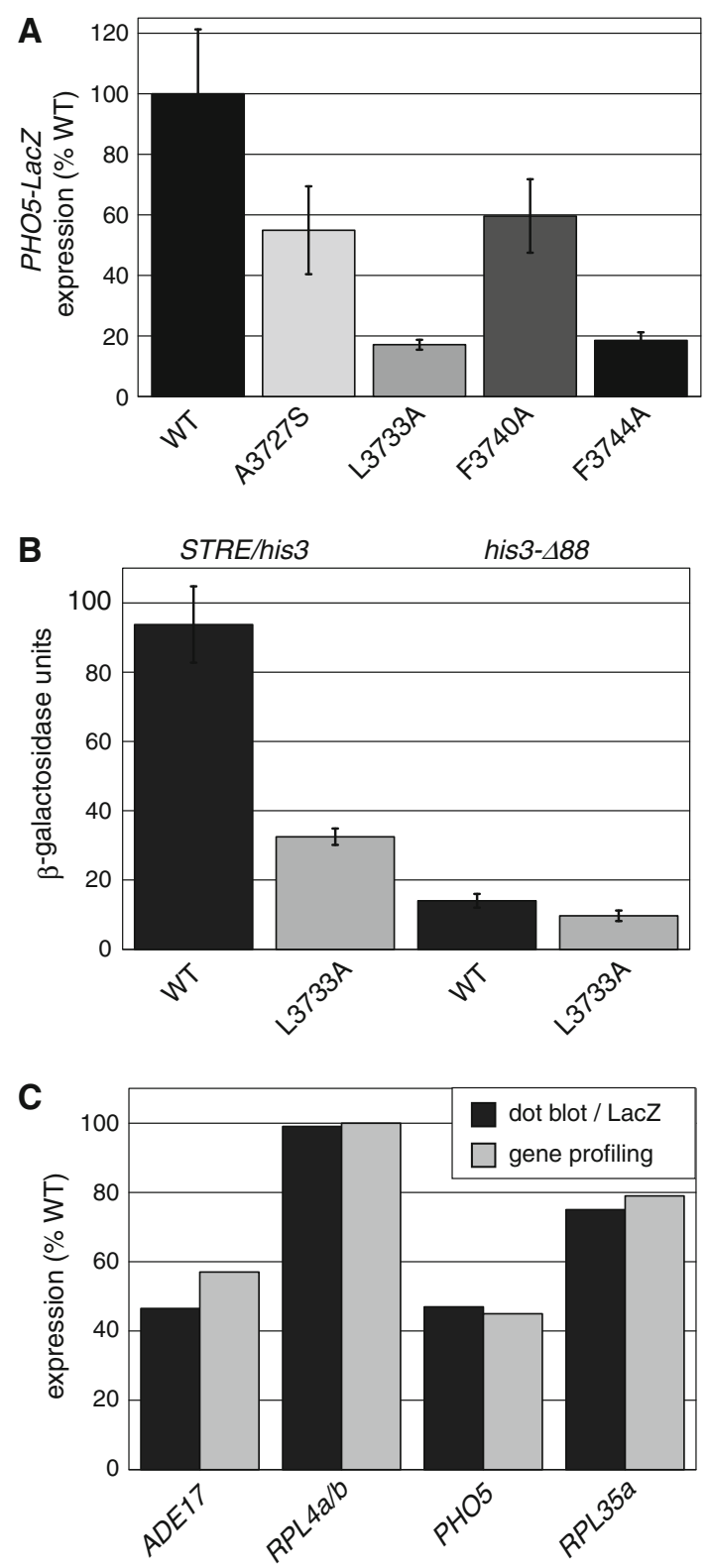

To address whether the expression changes determined for tral-L3733A resembled patterns seen with other mutations, we performed a hierarchical cluster analysis with the compendium dataset of Hughes et al. (2000), the datasets of strains containing deletions of NuA4 (Krogan et al. 2004) and SAGA components (Ingvarsdottir et al. 2005), and with the dataset of the PI3K-domain mutation tral-SRR3413 (Mutiu et al. 2007a) (Fig. 3a). Of the approximately 300 comparisons in the analysis, the gene expression profile of the strain containing tral-L3733A clustered closest to tralSRR3413. Other components of SAGA and NuA4 did not cluster within this leaf suggesting that the effects of tralL3733A result from the combined alteration of SAGA and NuA4 complexes and/or that Tra1 has one or more roles outside these complexes.
Fig. 2 Gene expression in the tral-L3733A strain. a The promoter region of $P H O 5$ was cloned as a $L a c Z$ reporter fusion into the $L E U 2$ centromeric plasmid YCp87 and transformed into yeast strains CY4353 (TRA1), CY4318 (tral-A3727S), CY4103 (tral-L3733A), CY4324 (tral-F3740A) and CY4350 (tral-F3744A), containing a plasmid copy of YHR100C. $\beta$-Galactosidase activity was determined after growth in low phosphate media for $15 \mathrm{~h}$ at $30^{\circ}$. Expression is shown as a percentage of that found for CY4353. Measurements were made in triplicate with the standard deviation indicated. b Expression from stress response elements. A cassette of two STRE elements was cloned into the EcoRI and SacI sites of his3-488-LacZ (Brandl et al. 1993) to give STRE-his3-LacZ. These elements replace the normal Gcn4 binding site in HIS3. STRE-his3-LacZ and his3- 488 were transformed into CY2706 and CY3003, and $\beta$-galactosidase assays performed after growth of cells in YPD containing 4\% ethanol. c Expression levels determined by gene profiling (GP, mRNA-Seq) as compared with RNA dot blots (ADE17 and RPL4a/b) and LacZ reporter fusions (PHO5 and RPL35a). RNA was prepared from yeast strains CY3003 (tral-L3733A) and CY2706 $\left(\right.$ TRA $\left._{W T}\right)$. mRNA-Seq libraries were constructed and sequencing performed on the Illumina/Solexa Genome Analyzer II platform. Comparisons between the strains were made as outlined in "Materials and methods". Similarly prepared RNA was spotted onto Hybond-N membrane and probed with singlestranded DNAs complementary to $A D E 17$ and $R P L 4 a / b$ RNA. Hybridization was detected by autoradiography and quantitated using AlphaImager 3400 software and shown as a percentage of wild-type expression. Expression of PHO5-LacZ and RPL35a-LacZ fusion reporters were determined after growth of CY3003 and CY2706 in YPD. Assays were performed in triplicate

The genome-wide occupancy profile of myc $_{9}$-Tra1 was determined to help assess whether the effect of Tral on gene expression is direct. As shown in Fig. 3b, there is a positive correlation between genomic occupancy of Tra1 and transcriptional frequency (Holstege et al. 1998), suggesting that Tra1 is recruited to actively transcribed genes. In addition, there was a positive correlation for the top quartile of Tra1 binding and Fhl1 $\left(p=2.2 \times 10^{-7}\right)$ and Rap1 $\left(p=1.1 \times 10^{-5}\right)$, likely related to the involvement of these factors and the NuA4 complex in regulating expression of ribosomal protein genes (Lieb et al. 2001; Rudra et al. 2005; Reid et al. 2000).

Intragenic suppressors of tral-L3733A

As a tool to evaluate mechanisms by which the L3733A mutation may affect Tra1 function, we selected random intragenic suppressor mutations that enable growth on media containing ethanol. A library of approximately 200 independent alleles was constructed by PCR mutagenesis of the C-terminal 2060 base pairs of the tral-L3733A allele. Mutations N3677D and T3716A were able to partially suppress the slow growth in YPD containing 4\% ethanol caused by the L3733A mutation (Fig. 4a) and restore transcription of PHO5-LacZ to approximately 70 and $80 \%$ of wild type, respectively (Fig. 4b). Both of the suppressor 
Table 4 Expression of genes most altered in CY3003 (tra1-L3733A)
${ }^{a}$ Values are the fold change in expression of CY3003 (tralL3733A) relative to CY2706 (TRA1) as determined from sequence profiling

b From the Saccharomyces Genome Database

\begin{tabular}{|c|c|c|c|}
\hline Locus & Gene & Fold change $^{\mathrm{a}}$ & Description $^{\mathrm{b}}$ \\
\hline YDR070C & FMP16 & 3.1 & Unknown \\
\hline YPL187W & $M F(\alpha) 1$ & 3.0 & Mating pheromone $\alpha$-factor \\
\hline YBR117C & $T K L 2$ & 2.7 & Transketolase: synthesis of aromatic amino acids \\
\hline YBR072W & $H S P 26$ & 2.6 & Heat shock protein: chaperone activity \\
\hline YKL163W & $P I R 3$ & 2.4 & Required for cell wall stability \\
\hline YGR109C & $C L B 6$ & 2.3 & B-type cyclin: DNA replication \\
\hline YHR033W & & 2.3 & Unknown \\
\hline YOL052C-A & $D D R 2$ & 2.2 & Multistress response protein \\
\hline YPL223C & GRE1 & 2.2 & Stress induced hydrophilin \\
\hline YCR007C & & 2.0 & Integral membrane protein \\
\hline YPR203W & & 2.0 & Unknown \\
\hline YHR136C & $S P L 2$ & -10.4 & Similar to cyclin-dependent kinase inhibitors \\
\hline YDR281C & PHM6 & -9.7 & Unknown \\
\hline YEL035C & UTR5 & -8.0 & Unknown \\
\hline YAR064W & & -4.3 & Unknown \\
\hline YAR071W & PHO11 & -4.0 & Acid phosphatase \\
\hline YDR379C-A & & -4.0 & Unknown \\
\hline YHR215W & PHO12 & -3.7 & Acid phosphatase \\
\hline YML123C & PHO84 & -3.1 & Inorganic phosphate and manganese transporter \\
\hline YKL053C-A & MDM35 & -3.1 & Mitochondrial intermembrane space \\
\hline YBR147W & $R T C 2$ & -2.9 & Similarity to G-protein coupled receptor \\
\hline YDL098C & $S N U 23$ & -2.8 & Component of U4/U6.U5 snRNP \\
\hline YKL120W & $O A C 1$ & -2.7 & Mitochondrial inner membrane transporter \\
\hline YBR050C & $R E G 2$ & -2.7 & Phosphatase regulatory subunit \\
\hline YNL155W & & -2.7 & Unknown \\
\hline YHR081W & $L R P 1$ & -2.6 & Exosome-associated nucleic acid binding protein \\
\hline YGL009C & LEU1 & -2.6 & Leucine biosynthesis \\
\hline YLR297W & & -2.4 & Unknown \\
\hline YLR346C & & -2.4 & Unknown \\
\hline YNR050C & LYS9 & -2.4 & Lysine biosynthesis \\
\hline YHR055C & CUP1-2 & -2.3 & Metallothionein \\
\hline YKL099C & UTP11 & -2.3 & Subunit of U3-containing small subunit processome \\
\hline YGR129W & $S Y F 2$ & -2.3 & Pre-mRNA splicing \\
\hline YDL182W & LYS20 & -2.3 & Lysine biosynthesis \\
\hline YLL009C & COX17 & -2.3 & Copper metallochaperone \\
\hline YLR262C & YPT6 & -2.3 & Ras-like GTP binding protein involved in secretion \\
\hline YJR057W & $C D C 8$ & -2.3 & Thymidylate and uridylate kinase \\
\hline YDR471W & $R P L 27 B$ & -2.3 & Ribosomal subunit \\
\hline YNL214W & PEX17 & -2.3 & Peroxisomal membrane peroxin \\
\hline YBR093C & PHO5 & -2.3 & Acid phosphatase \\
\hline YOL014W & & -2.3 & Unknown \\
\hline YDR288W & NSE3 & -2.3 & Mms21-Smc5-Smc6 complex subunit \\
\hline YLR159C-A & & -2.2 & unknown \\
\hline YJR159W & SOR1 & -2.2 & Sorbitol dehydrogenase \\
\hline YMR294W & $J N M 1$ & -2.2 & Component of the dynactin complex \\
\hline YJL190C & RPS22A & -2.2 & Ribosomal subunit \\
\hline YLR442C & $\operatorname{SIR} 3$ & -2.2 & Chromatin silencing \\
\hline YHR053C & CUP1-1 & -2.2 & Metallothionein \\
\hline YIR034C & LYS1 & -2.1 & Lysine biosynthesis \\
\hline YJL200C & $A C O 2$ & -2.1 & Putative mitochondrial aconitase \\
\hline YOR044W & $\operatorname{IRC} 23$ & -2.1 & Unknown \\
\hline
\end{tabular}




\section{A}
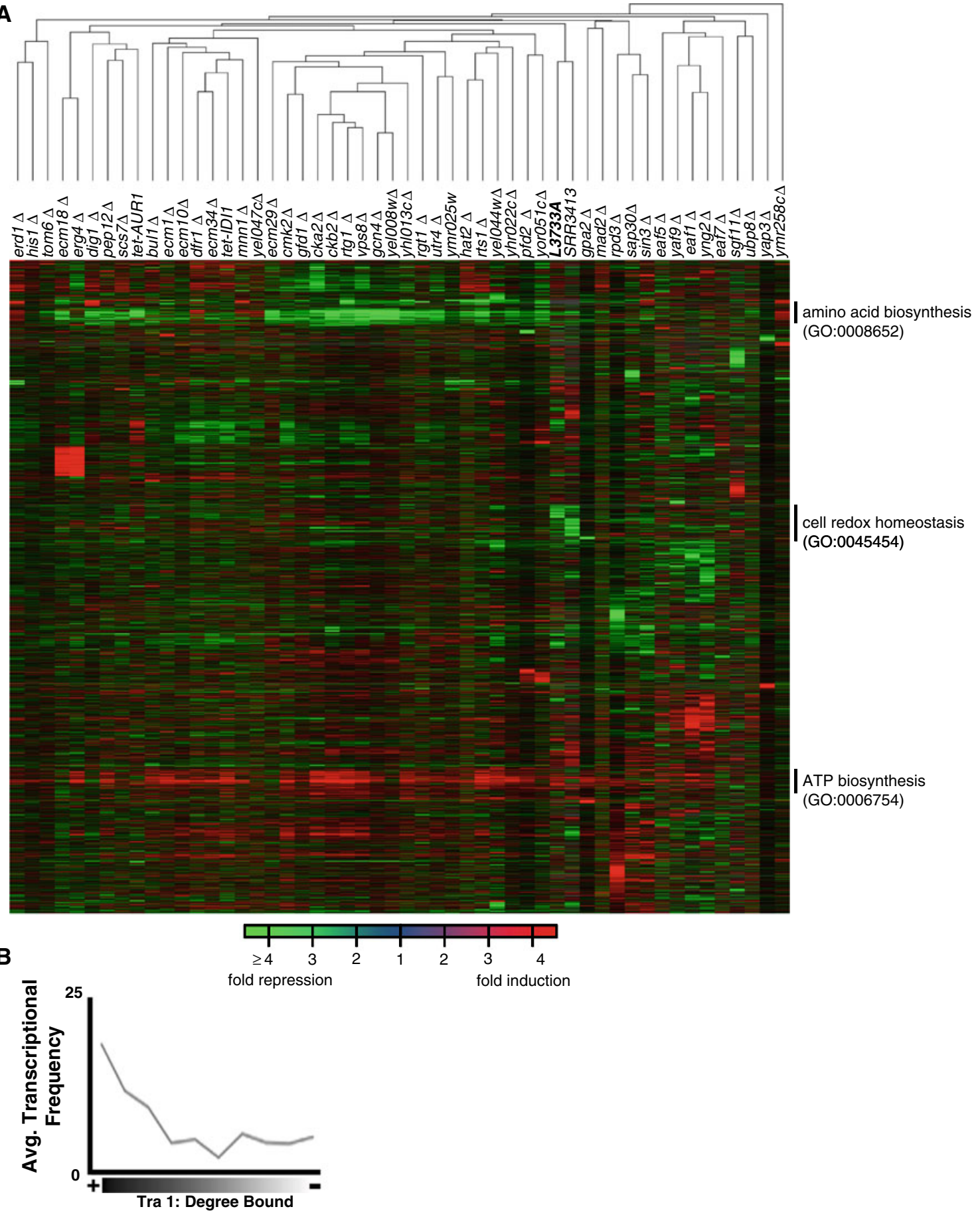

Fig. 3 Gene expression in the tral-L3733A strain. a Hierarchical cluster analysis. Comparisons were initially made with the compendium data set (Hughes et al. 2000), profiles from strains with deletions of NuA4 (Krogan et al. 2004) and SAGA components (Ingvarsdottir et al. 2005), and with tral-SRR3413 (Mutiu et al. 2007a). The diagram shows those profiles clustering in closest proximity to tral-L3733A. Gene fam-

mutations occur at positions that are not highly conserved within the Tra1/TRRAP family. N3677 is at the C-terminal end of the PI3 K domain, while T3716 is within the FATC domain.

ilies are indicated on the right. b Correlation between degree of Tra1-binding and average transcriptional frequency. Genome-wide localization studies were performed in triplicate for yeast strain CY2706 ( $\left.m y c_{9}-T R A 1\right)$ grown at $30^{\circ}$ in YPD, essentially as described (Yu et al. 2004). The average transcription frequency of each gene (Holstege et al. 1998) is plotted versus the relative binding of $m y c_{9}-$ TRAl

\section{Expression of Tra1-L3733A and Tra1-G3745}

We used Western blotting to determine the steady-state lev-

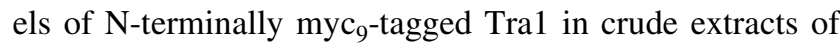



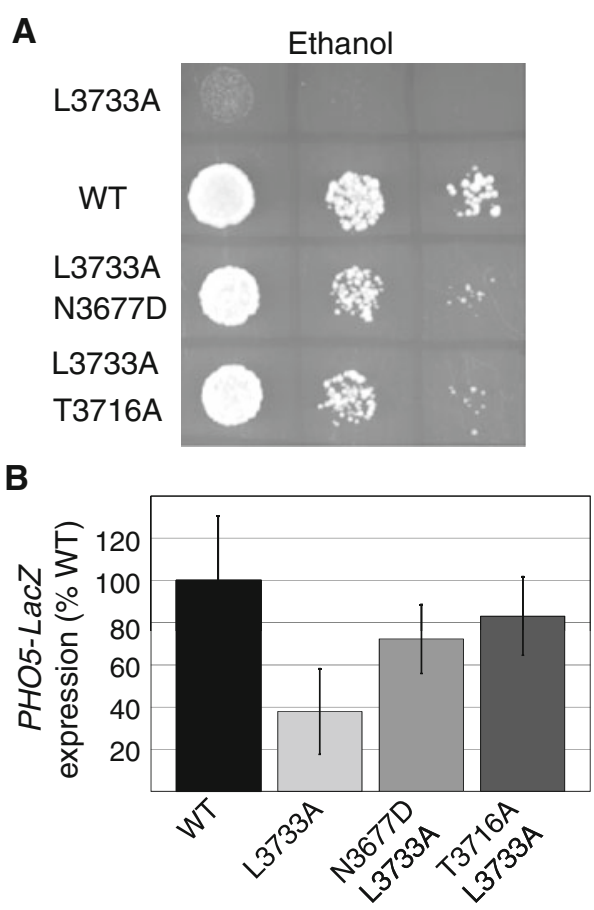

Fig. 4 Intragenic supressors of the $L 3733 A$ mutation. a Yeast strains CY3003 (tral-L3733A), CY2706 (TRA1 ${ }_{W T}$ ), CY4055 (tral-L3733A/ $N 3677 D$ ) and CY4056 (tral-L3733A/T3716A) were grown in minimal media and tenfold serial dilutions spotted onto a YPD plate containing 4\% ethanol. b PHO5-LacZ expression. The above strains containing YCp87-PHO5-LacZ were grown to saturation in minimal media lacking leucine, diluted sixfold in YPD depleted of phosphate and grown for $15 \mathrm{~h}$ at $30^{\circ} . \beta$-Galactosidase activity was calculated for each strain in triplicate and plotted as a percentage of that found for CY2706

yeast strains CY2706 (Tra $_{\text {WT }}$ expressed from the DED1 promoter) and CY3003 (Tra1-L3733A expressed from the DED1 promoter). As shown in Fig. 5a, Tra1-L3733A was reduced compared with wild-type Tra1. The profile of proteolytic products also differed for the wild-type and mutant proteins (compare lanes 2 and 4). A similar reduction of Tra1-L3733A was seen when cells were disrupted under denaturing conditions (not shown). As shown in Fig. 5b and quantified in Fig. 5c, the second site mutations N3677D and T3716A partially restored Tra1 levels and to an extent that paralleled their restoration of function. This correlation suggests that the phenotype of tra-L3733A is related to the reduced steady-state level of the protein.

The cellular concentration of myc $_{9}$-Tra1-G3745 was analyzed in a strain containing untagged wild-type Tra1 since tral-G3745 does not support viability. The extreme slow growth of this strain made recovery of the protein difficult. We estimate that Tra1-G3745 was present at a level approximately $5 \%$ of wild-type (not shown) suggesting that the precise location of the C-terminal carboxyl group is critical for the stability of Tra1.

The NuA4 complex is localized to the PHO5 promoter prior to gene activation (Nourani et al. 2004). As another measure of the relative level of Tra1-L3733A in vivo, we determined the extent of histone $\mathrm{H} 4$ acetylation at the PHO5 promoter after growth of TRA $1_{W T}$ and tral-L3733A strains in YPD. Chromatin immunoprecipitations were performed with anti-acetylated histone $\mathrm{H} 4 / \mathrm{K} 8$ antibody and to allow normalization, with anti-histone $\mathrm{H} 3$ antibody. As shown in Fig. 5d, under conditions in which total histone H3 was relatively unchanged (lanes 2-4), the L3733A mutation reduced histone $\mathrm{H} 4$ acetylation at $\mathrm{PHO5}$ by approximately threefold (lanes 5-7).

If the effects of the L3733A mutation result primarily from decreased stability of Tra1, we would expect that reducing the wild-type protein would cause a similar phenotype. Cells containing wild-type Tra1 under control of the methionine-repressed MET3 promoter (Mao et al. 2002) $\left(\right.$ MET3-Tra $\left._{\mathrm{WT}}\right)$ were grown in minimal media with increasing concentrations of methionine and in the presence or absence of 3\% ethanol. As shown in Fig. 6, in media lacking methionine MET3-Tra1 ${ }_{\mathrm{wT}}$ supported growth in both media at a level comparable to DEDl-expressed $\mathrm{Tra}_{\mathrm{WT}}$. In as little as $5 \mu \mathrm{M}$ methionine, reduced expression of MET3-Tra $1_{\mathrm{WT}}$ resulted in decreased growth of the strain in YPD and increased sensitivity to ethanol, which resembled that seen for the L3733A mutation (expressed from the $D E D 1$ promoter). We note that at elevated concentrations of methionine, fast-growing suppressors were evident with the strain containing MET3-Tra $1_{\mathrm{WT}}$, likely arising from derepression of the MET3 promoter or increased plasmid copy number. Given the number of generations required to obtain detectable amounts of Tra1, these suppressors made it difficult to compare the exact level of Tra1 in the presence of methionine.

Molecular interactions of Tra1-L3733A and Tra1-G3745

The ability of Tra1-L3733A to associate with SAGA and NuA4 components was compared to wild-type Tra1 and the

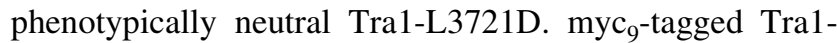
L3721D, Tra1-L3733A, and Tra $1_{\mathrm{WT}}$ were expressed in a strain containing TAP-ADA2 (Ghaemmaghami et al. 2003), and tandem affinity purification performed on crude yeast extracts. As shown in Fig. 7a, Tra1-L3721D and Tra1L3733A co-purified with Ada2 at levels comparably to wild-type Tra1. Similarly, neither mutation affected interaction with TAP-Spt7 or with TAP-Esa1 (Fig. 7b). To determine if the L3733A mutation affects Tra1's ability to interact with transcriptional activators, we analyzed the binding of Tra1-L3733A to the activation domain of Gal4 $\left(\mathrm{Gal}_{\mathrm{AD}}\right)$. $\mathrm{Myc}_{9}$-tagged $\mathrm{Tra}_{\mathrm{WT}}$ and Tra1-L3733A were purified via association with TAP-tagged Ada2. The affinity-purified SAGA complex was then chromatographed on GST-Gal4 $_{\mathrm{AD}}$ columns and the association of Tra1 determined after elution with glutathione by Western blotting. 

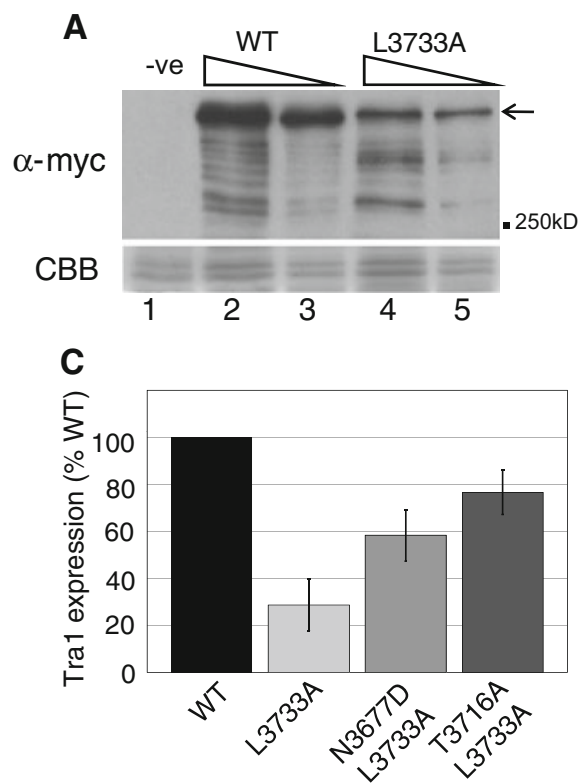

Fig. 5 Expression of the tral-L3733A and tral-G3745 alleles. a Whole cell extracts were prepared from yeast strain KY320 (-ve, lane 1) or strains expressing myc $_{9}$-tagged versions of $\operatorname{Tra}_{\mathrm{WT}}$ (lanes 2,3 ) or Tra1-L3733A (lanes 4, 5). Extract was separated by SDS PAGE (5\%) and Western blotted with anti-myc antibody. The upper panel is the Western blot with anti-myc antibody. The full length myc $_{9}$-Tralof $\sim 450 \mathrm{kDa}$ and the mobility of a $250-\mathrm{kDa}$ marker protein are indicated with an arrow and dot, respectively. The lower panel is a portion of an equivalent gel stained with Coomassie Brilliant Blue (CBB). Lanes 1, 3 , and 5 contain $50 \mu \mathrm{g}$ of protein; lanes 2 and $4,100 \mu \mathrm{g}$. b Levels of Tra1-L3733A suppressors. CY2706 $\left(\mathrm{myc}_{9}-\mathrm{Tra}_{\mathrm{WT}}\right.$, lanes 1, 2), CY3003 (myc ${ }_{9}$-Tra1-L3733A, lanes 3, 4), CY4055 (myc ${ }_{9}$-Tra1N3677D/L3733A lanes 5, 6), and CY4056 (myc ${ }_{9}$-Tra1-T3716A/ L3733A lanes 7,8 ) were grown to $A_{600}=2.0$. Crude protein was isolated by bead lysis and $50 \mu \mathrm{g}$ (even numbered lanes) and $100 \mu \mathrm{g}$ (odd
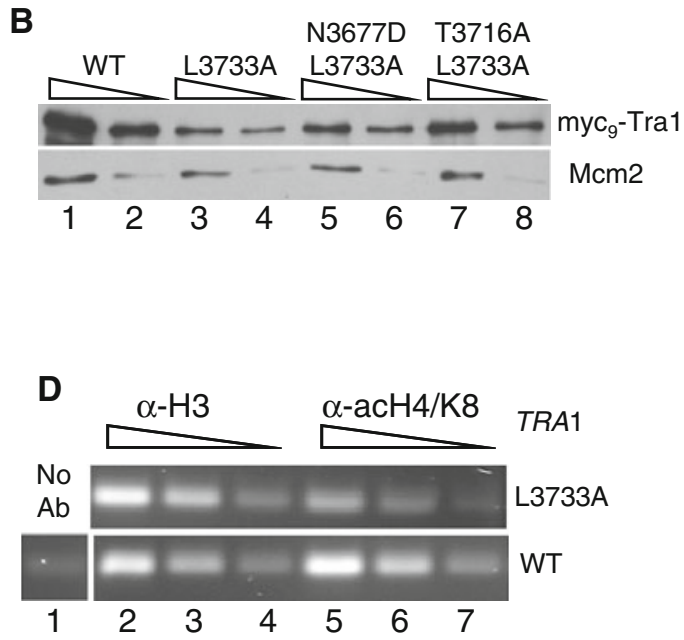

numbered lanes) was separated by SDS-PAGE and Western blotted with anti-myc or anti Mcm2 antibodies. Expression of tral-G3745. c Quantitation of Tra1 levels. The Western blot as in B was performed in triplicate with independently grown cultures. Relative amounts of Tra1 were determined by densitometry using AlphaImager 3400 software. d Histone $\mathrm{H} 4$ acetylation. Chromatin was isolated from yeast strains CY2706 (TRA1 $1_{W T}$, lower panel) or CY3003 (tral-L3733A, upper panel) grown to $A_{600}=2.0$ in YPD. Chromatin was immunoprecipitated with antibody to histone $\mathrm{H} 3$ (lanes 2-4) and histone $\mathrm{H} 4$ acetylated at K8 (lanes 5-7), then analyzed by PCR with primers for PHO5 promoter sequences. Consecutive samples represent twofold serial dilutions of the DNA to enable quantitation. Lane 1 is a mock experiment with no histone antibody performed with a wild-type extract at $2 \times$ concentration
Fig. 6 Reduced expression of Tra1 results in ethanol sensitivity. Yeast strains CY3003 (DED1 promoter: tral-L3733A), CY2706 (DED1 promoter: TRA $\left.1_{W T}\right)$, and CY3021 (MET3 in minimal media lacking methionine, and then serial dilutions were spotted onto minimal plates containing the indicated concentration of methionine and for the lower panel 3\% ethanol promoter: $T R A 1_{W T}$ ) were grown

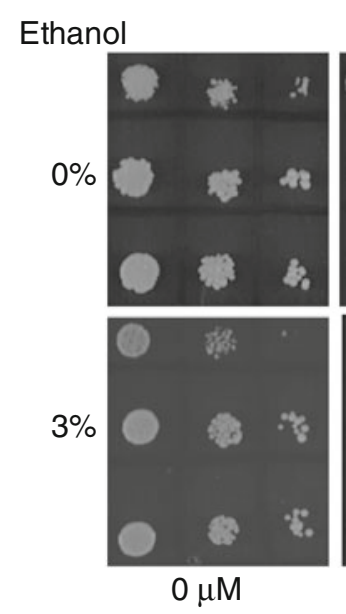

As shown in Fig. 7c, Tra1-L3733A interacted with the activation domain of Gal4 to approximately the same extent as wild-type Tra1.

Since tral-G3745 does not support viability, interaction of myc $_{9}$-Tra1-G3745 with TAP-tagged Esa1, Spt7, and

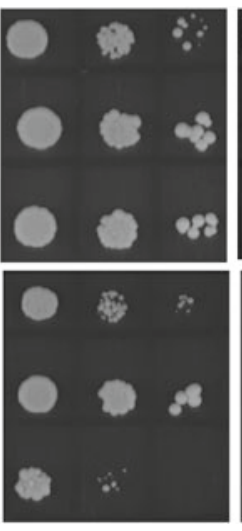

$5 \mu \mathrm{M}$
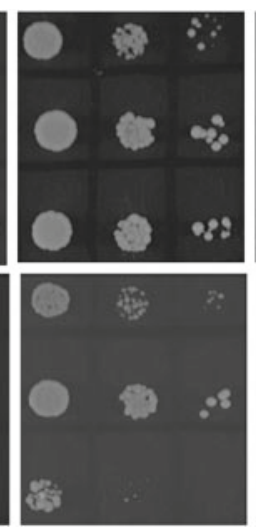

$10 \mu \mathrm{M}$

Promoter Allele

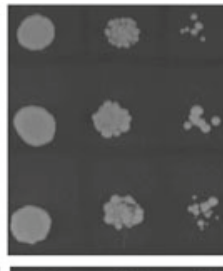

DED1 L3733A

DED1 WT

MET3 WT

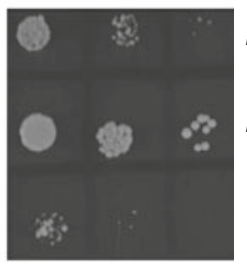

DED1 L3733A

DED1 WT

MET3 WT

\section{Methionine}

Ada2, was analyzed in strains also containing untagged wild-type Tra1. Crude extracts were tandem affinity purified and the level of myc $_{9}$-Tral determined by Western blotting. After normalizing for the level of input Tra1, the amount of Tra1-G3745 co-purifying with Spt7 and Esa1 
A

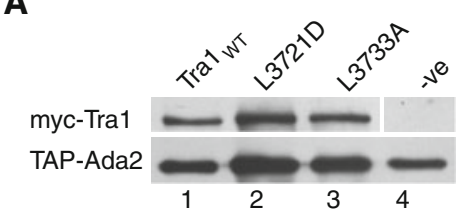

C



D
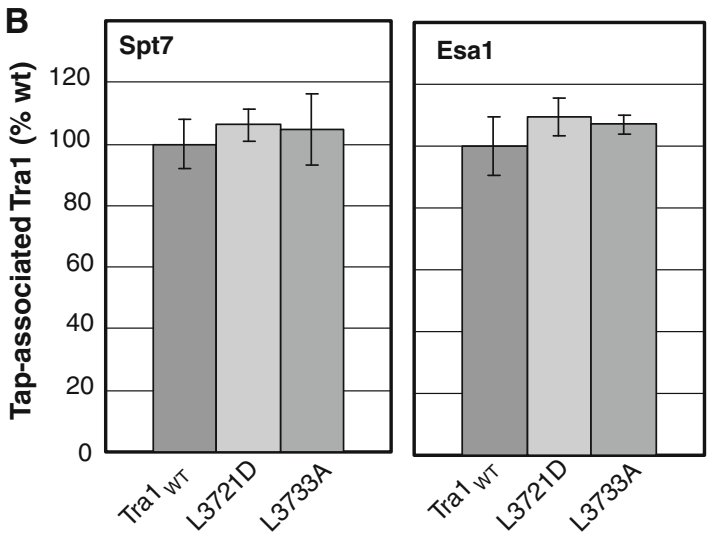

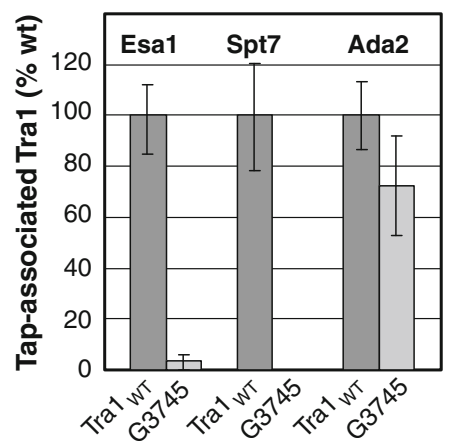

Fig. 7 Protein interactions of Tral-L3733A and Tral-G3745. a Interaction with Ada2. Crude extracts were prepared from an $A D A 2-$ TAP strain (Ghaemmaghami et al. 2003) expressing myc -Tra $_{\mathrm{WT}}$

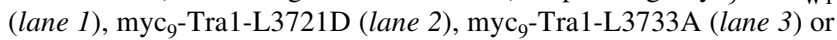
only the genomic TRA1 (-ve, lane 4). Volumes corresponding to equal amounts of myc-tagged Tra1 were subject to tandem affinity purification and equal volumes Western blotted using anti-myc antibody (upper panel) or anti-CBP (lower panel). b Interaction with Spt7 and Esa1. Crude extracts of SPT7-TAP and ESA 1-TAP strains expressing myc - $^{-}$ $\mathrm{Tra}_{\mathrm{WT}}$, myc $\mathrm{c}_{9}$-Tra1-L3721D, or myc $\mathrm{c}_{9}$-Tra1-L3733A were analyzed as above and scanned using AlphaImager 3400 software. The ratio of the Spt7 and Esa1-associated to input Tra1 is presented as percent of wild type. The experiments were performed in triplicate with the associated standard error indicated. c Interaction of Tra1-L3733A with GST$\mathrm{Gal}_{\mathrm{AD}}$. myc $_{9}-\mathrm{Tra}_{\mathrm{WT}}$ or myc $_{9}$-Tra1-L3733A was expressed in yeast strain CY2998 containing TAP-tagged Ada2. After CBP affinity purification approximately equal amounts of $\mathrm{Tra}_{\mathrm{WT}}$ (lanes 1,2 ) or Tra1-L3733A (lanes 3, 4), as determined by Western blotting, were incubated with GST-Gal4 ${ }_{\mathrm{AD}}$ bound to glutathione-Sepharose. After washing, three fractions were eluted with glutathione and Western blotted for the presence of Tra $1_{\mathrm{WT}}$ (lanes 5, 7 and 9) or Tra1-L3733A (lanes 6, 8 and 10). The levels of bound Tra $1_{\mathrm{WT}}$ and Tra1-L3733A correlated with the elution profile of GST-Gal4 ${ }_{\mathrm{AD}}$ (not shown). d Tra1G3745. Crude extracts were prepared from the ESA1-TAP, SPT7-TAP, or ADA2-TAP strains (Ghaemmaghami et al. 2003) expressing $m y c_{9^{-}}$ $T R A 1_{W T}$ or $m y c_{9}-T R A 1-G 3745$. Extracts were tandem affinity purified. Equal volumes were separated by SDS PAGE and Western blotted using anti-myc antibody to detect Tra1 or anti-CBP for Esa1, Spt7, or Ada2. AlphaImager 3400 software was used for densitometric analysis. The ratio between the purified and the input amounts is presented as percent of wild type. The experiments were performed in duplicate with the range as indicated was diminished to $<5 \%$, of that found for wild-type Tra 1 (Fig. 7d). Normal positioning of Tra1's C-terminal carboxyl group is thus required for formation of SAGA and $\mathrm{NuA} 4$ complexes. Interestingly, the additional C-terminal glycine only partially reduced $(\sim 70 \%)$ the interaction with Ada2, suggesting that Tra1 has more than one interaction site with components of SAGA.

\section{Genetic interactions of tral-L3733A}

To investigate the relationship between the PI3K and FATC domains, we constructed the double-mutant allele, tral-SRR3413/L3733A and examined its ability to support viability after plasmid shuffling in yeast strain CY1021. Transformation of a TRPI centromeric plasmid expressing Tra1-SRR3413/L3733A resulted in slow-growing colonies, suggesting a dominant negative effect of this allele (not shown). In addition, no colonies possessed the double- mutant allele (tral-SRR3413/L3733A) after plasmid shuffling on 5-FOA. We conclude that the tral-SRR3413/L3733A allele does not support viability and that the effects of PI3K and FATC domain mutations are additive.

tral-L3733A was introduced into a group of the knockout collection of strains (Winzeler and Davis 1997) to examine genetic interactions with SAGA and NuA4 component genes (Table 5). Growth of the double mutants was compared with either single mutant on YPD and YPD containing 3\% ethanol. (As shown above, in the BY4741/4742 strain background tral-L3733A alone only causes a minor growth defect in 3\% ethanol; sensitivity is seen at $6 \%$ ethanol.) In YPD media, synthetic slow growth/lethality was observed with deletions of some but not all components. tral-L3733A was synthetically lethal with spt204 and severe slow growth was seen with adal $\triangle$ tral-L3733A and eaf14 tral-L3733A. Ada1 and Spt20 have roles in the structural integrity of SAGA (Sterner et al. 1999; Wu and 
Table 5 Growth of double mutants of tral-L3733A with deletions of SAGA and NuA4 components

\begin{tabular}{|c|c|c|c|c|}
\hline \multirow[t]{2}{*}{ Deletion $^{\mathrm{a}}$} & \multicolumn{2}{|l|}{$\mathrm{YPD}^{\mathrm{b}}$} & \multicolumn{2}{|c|}{$\mathrm{YPD}+3 \% \mathrm{EtOH}^{\mathrm{d}}$} \\
\hline & TRA1 & $L 3733 A$ & TRA1 & $L 3733 A$ \\
\hline None (wt) & ++++ & +++ & ++++ & +++ \\
\hline $\operatorname{gcn} 5$ & +++ & $+1-$ & + & $+/-$ \\
\hline ada2 & +++ & + & + & $+/-$ \\
\hline$n g g 1$ & +++ & + & + & $+/-$ \\
\hline spt3 & +++ & +++ & +++ & + \\
\hline spt8 & +++ & +++ & +++ & + \\
\hline ubp 8 & ++++ & +++ & +++ & + \\
\hline $\operatorname{sgfl1}$ & ++++ & +++ & +++ & ++ \\
\hline $\operatorname{sgf73}$ & +++ & + & +++ & $+1-$ \\
\hline spt 20 & + & $\mathrm{sl}^{\mathrm{c}}$ & $+/-$ & sl \\
\hline adal & ++ & $+/-$ & $+1-$ & - \\
\hline $\operatorname{sgf} 29$ & ++++ & ++ & +++ & + \\
\hline eafl & ++ & $+1-$ & + & - \\
\hline eaf3 & +++ & ++ & ++++ & + \\
\hline eaf7 & +++ & +++ & +++ & ++ \\
\hline
\end{tabular}

${ }^{a}$ Single mutants and the wild-type strain BY4741 (87) were obtained from Open Biosystems. Double mutants were made by mating of CY4057 or CY4103 with the indicated deletion strain from the consortium collection, followed by sporulation and selecting for HIS $+\mathrm{Kan}^{r}$ spore colonies

${ }^{b}$ Strains were scored for relative growth on YPD or YPD plus 3\% ethanol after 2 days at $30^{\circ}$. Scoring for the two sets of plates was done independently with ++++ being the most rapid growth observed in each condition

${ }^{c}$ Synthetic lethal, no HIS+ $\mathrm{Kan}^{r}$ spore colonies were obtained

d The tral-L3733A alone in the BY4741/4742 strain background, only slightly affects growth in $3 \%$ ethanol; sensitivity is seen at $6 \%$

Winston 2002), whereas Eaf1 is required for the integrity of the NuA4 complex (Auger et al. 2008; Babiarz et al. 2006). Similar synthetic lethality is found for double mutants of adal $\Delta$ and spt204 with deletions of NuA4 components, and eafl $\Delta$ with deletions of SAGA components (Lin et al. 2008, Mitchell et al. 2008). tral-L3733A also resulted in synthetic slow growth in combination with disruptions of gcn5, ada2, ngg1, sgf29, and sgf73. In contrast, additive growth defects on YPD were not as pronounced with double mutants of tral-L3733A with spt3A, spt8A, sgf11A, ubp $8 \Delta$, eaf $3 \Delta$, and eaf7 $\Delta$. Synthetic slow growth was observed for all the deletion combinations when cells were grown in media containing 3\% ethanol. This implies that fully functional $\mathrm{NuA} 4$ and SAGA complexes are required under conditions of stress and that the effects of tral$L 3733 A$ are additive with all functions of these complexes.

Larschan and Winston (2001) found that deletions of hdal and nhp10 suppress phenotypes resulting from disruption of spt20, an integral component of the SAGA complex. To determine if the effect of tral-L37733A is related to a similar loss of function as spt20, we analyzed whether $h d a l \Delta 0$ and nhpl 10 suppress tral-L3733A. Growth of double-mutant strains was analyzed on YPD at $16^{\circ}, 30^{\circ}$, and $37^{\circ}$ and YPD containing 6\% ethanol (Fig. 8). Under none of these conditions was the slow growth caused by tral-L3733A suppressed by deletion of either $h d a l$ or $n h p 10$. This result supports the view that the phenotypes arising from tral-L3733A are not due solely to Tra1's action in the SAGA complex.

\section{Discussion}

Tra1 functions revealed by FATC domain mutations

Our studies demonstrate the consequences of reduced Tra1 function on gene expression. Mutation of L3733A resulted in decreased activation of $\mathrm{PHO} 5$ and STRE/his 3 promoters, and a twofold or greater change in expression of $\sim 90$ genes in rich media. The effects of tral-L3733A are likely mediated through partial loss of both SAGA and NuA4 function rather than loss of either individual complex. This is consistent with the phenotypic similarities between the tralL3733A strain and strains with deletions of components of NuA4 and SAGA, the additive effects of these mutations, and the inability of the tral-L3733A allele to be suppressed by deletion of either hdal or nhplo.

When considered together, the phenotypes displayed by the tral-FATC mutant strains reveal a role for Tra1 in responding to a variety of stress conditions. Growth defects included temperature sensitivity and slow growth in media containing ethanol, calcofluor white, tert-butylhydroperoxide, and tunicamycin. The latter three indicate deficiencies in pathways required for cell wall integrity, response to oxidative stress and the unfolded protein response, respectively. A requirement for Tra1 in responding to nutrient levels is apparent from the sensitivity to rapamycin. As evident by the reduced expression from PHO5 and STRE/his3 promoters in the tral-L3733A strain, the stress-related phenotypes may be due to the inability of the FATC mutants to activate the expression of genes required to manage the stress. This interpretation agrees with the general finding that many SAGA-regulated genes fall into the category of stress-induced (Huisinga and Pugh 2004).

The tral-L3733A strain did not possess all the phenotype characteristic of deletions of SAGA and NuA4 components. This suggests that some activities of the SAGA and $\mathrm{NuA} 4$ complexes are relatively unaffected by reduced levels of Tra1. For example unlike strains with deletions of the $A D A$ genes (Berger et al. 1992), the tral-L3733A strain is sensitive to VP16 overexpression. This could occur if sensitivity to VP16 requires minimal SAGA-mediated acetylation, or alternatively, sensitivity can result from Gcn5 activity independent of Tra1. The possibility of the latter is 


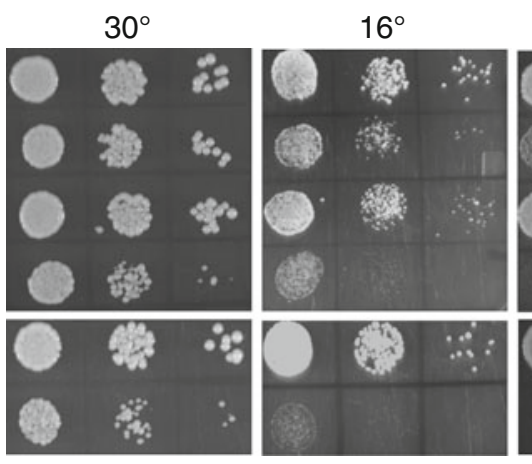

Fig. 8 Deletion of hdal or nhp10 does not suppress tral-L3733A. Strains deleted for $h d a 1$ or $n h p 10$ were generated by sporulation of diploid deletion strains obtained from Open Biosystems. Double mutants with tra1-L3733A were obtained by mating with CY4057 or CY4103 $37^{\circ}$

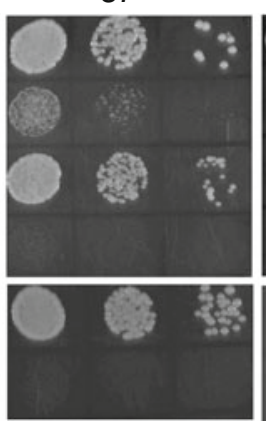

Ethanol

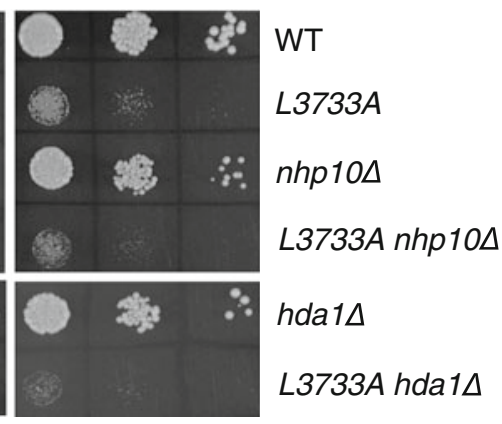

and sporulation. The wild-type strain BY4742, and the single- and double-mutant strains were grown in YPD and serial dilutions spotted onto YPD at $30^{\circ}, 16^{\circ}$ or $37^{\circ}$, or YPD containing $6 \%$ ethanol at $30^{\circ}$ consistent with biochemical evidence for an Ada complex (Eberharter et al. 1999; Saleh et al. 1997).

\section{The FATC domain is required for Tra1 stability}

We evaluated potential mechanisms for the decreased function of Tra1-L3733A. Since Tra1-L3733A interacted with the Gal4 activation domain and components of SAGA and NuA4 comparably to wild-type, the most straightforward explanation was its approximately fourfold reduced cellular concentration. Consistent with this model, similar growth defects are observed when the expression of wild-type Tra1 is decreased. Furthermore, intragenic suppressors of the L3733A mutation that increase activity restore Tral levels to a similar extent.

The reduced cellular concentration and altered proteolytic profile of Tra1-L3733A suggest a role for the FATC domain in maintaining the molecule's three-dimensional structure. Spagnolo et al. (2006) found that the FATC domain of DNA-PKes is involved in a conformational change that place it in close proximity to HEAT repeat sequences found toward the N-terminus. We speculate that the FATC domain of Tra1 may directly or indirectly, have a comparable role in determining conformation and that destabilizing this structure would result in enhanced sensitivity to proteolytic cleavage. In such a model suppression of L3733A by T3716A and N3677D may occur through reducing proteoytic degradation, perhaps through stabilizing necessary molecular interactions.

To directly compare the half-life of Tra1-L3733A with wild-type Tra1 we analyzed protein levels after cycloheximide arrest of translation. Conclusions from these experiments were limited because of minimal turnover of Tra1 after cycloheximide arrest. Because of this we have also considered possible effects of the L3733A mutation on aspects of the expression of Tra1. It is unlikely that transla- tional control is affected by L3733A because this would not easily account for the conservation of L3733 across species and in the PIKK family, the observed second-site suppression, or the altered proteolytic pattern. Nor does the inserted GCA codon show a negative bias. The level of Tra1-L3733A is also not likely the result of altered transcription since gene profiling data indicates only marginally reduced expression of $D E D I$ (the promoter for the plasmid copies of TRAl) and the phenotypes are observed when the L3733A mutation is expressed from its native promoter or the Met3 promoter (not shown). This being said, we cannot exclude contributions from more complex mechanisms: for example, the stabilization, processing or nuclear export of its mRNA transcript.

Dames et al. (2005) determined the structure of the Tor1 FATC domain in solution. They observed an extended $\alpha$-helix that was interrupted by a hairpin followed by a candy cane-like loop for the terminal five residues, held in place by a disulfide bridge at positions that correspond to 3734 and 3741 of Tra1. In the Tor 1 structure, the leucine equivalent to L3733 of Tra1 is positioned proximal to its terminal tryptophan where a hydrophobic interaction could potentially stabilize the conformation of the loop. We do not believe a similar structure exists for the FATC domain of Tral since the cysteines are not found in Tra1, nor is a glycine found within the loop that would facilitate the bend. In addition, while mutation of the terminal phenylalanine reduced growth, the phenotypic profile did not resemble tral-L3733A. We also evaluated the possible importance of a hydrophobic patch created by extending the $\alpha$-helix to the extreme C-terminus of Tral and the formation of a surface including L3733, F3740, and F3744. We conclude that if the extended helix is formed, the integrity of the hydrophobic patch is not likely important because mutation of F3740 to alanine did not result in obvious growth defects. 
Integrity of the extreme C-terminus of Tra1 is essential for function

Being a 3744-residue protein, it seems unlikely that the C-terminus of Tra1 has a role in the innate folding of the protein. Rather, the reduced interaction of Tra1-G3745 with Esa1 and Spt7 support a model whereby the C-terminus is involved in protein-protein interactions necessary for function and stability of the protein. The extreme C-terminal sequences of Tra1 resemble the hydrophobic termini found for the interacting partners of PDZ domains (Tonikian et al. 2008) and the C-terminal phenylalanine of TraD, a protein required for bacterial $\mathrm{F}$ plasmid conjugation. Crystal structures of the TraD-TraM interaction show precise alignment of the TraD C-terminus with TraM (Lu et al. 2008). This interaction is disrupted by a glycine addition to TraD. The combination of the charged C-terminus on a hydrophobic residue creates a highly specific interaction site not otherwise found on the protein surface (Lu et al. 2008).

Sun et al. (2005) have shown that mutations within the FATC domain of ATM affect its interaction with Tip60. We analyzed whether a C-terminal fragment of Tra1 including PI3K and FATC domains is sufficient for interaction with Esa1, the yeast counterpart of Tip60, using both bacterially expressed proteins and two-hybrid analysis. In neither case was an interaction detected (not shown). This implies that other regions of Tra1 are also required for the interaction or that Esa1 is not a direct target of the FATC domain. Nevertheless, the finding that Tra1-G3745 associates poorly with Esa1 and Spt7 suggests that the C-terminus functions, at least in part, through protein-protein interactions.

tral-G3745 and to a lesser extent tral-L3733A act in a dominant negative fashion. This may seem inconsistent with their loss of function. We favor the idea that the dominant negative nature of these alleles is due to high levels of partial complexes and/or Tra1 proteolytic products since for tral-G3745 and tral-L3733A there was an inverse relationship between the extent to which the allele was dominant negative and its cellular concentration.

Recently, Tra1 has been found associated with a group of proteins including Rvb1, Rvb2, Asa1, Tel2, Tti1, and Tti2, all of which are essential (Shevchenko et al. 2008). While the exact composition and function of this ASTRA (for ASsembly of Tel, Rvb and Atm-like kinase) complex (Shevchenko et al. 2008) is unknown, we cannot exclude the possibility that some of the deficiencies associated with the FATC mutants result from changes in their association with these proteins.

Acknowledgments This work was supported by a Canadian Institutes of Health Research grant to CJB (MOP10845). SMTH was supported by a Frederick Banting and Charles Best Canada Graduate Scholarship sponsored by the CIHR, and AIM and SK by Western Graduate Scholarships. We would like to thank Mark Glover for com- municating results prior to publication and suggesting the G3745 experiment, Fred Winston and Jacques Côté for yeast strains, and Megan Davey, David Edgell, Brian Shilton and David Haniford for comments on the manuscript.

Open Access This article is distributed under the terms of the Creative Commons Attribution Noncommercial License which permits any noncommercial use, distribution, and reproduction in any medium, provided the original author(s) and source are credited.

\section{References}

Abraham RT (2004) PI 3-kinase related kinases: 'big' players in stressinduced signaling pathways. DNA Repair 3:883-887

Allard S, Utley RT, Savard J, Clarke A, Grant P, Brandl CJ, Pillus L, Workman J, Côté J (1999) NuA4, an essential transcription adaptor/histone $\mathrm{H} 4$ acetyltransferase complex containing Esalp and the ATM-related cofactor Tra1p. EMBO J 18:5108-5119

Auger A, Galarneau L, Altaf M, Nourani A, Doyon Y, Utley RT, Cronier D, Allard S, Côté J (2008) Eaf1 is the platform for NuA4 molecular assembly that evoluntionarily links chromatin acetylation to ATP-dependent excahange of histone H2A variants. Mol Cell Biol 28:2257-2270

Ausubel FM, Brent R, Kingston RE, Moore DD, Seidman JG, Smith JA, Struhl K (1988) Current protocols in molecular biology. Greene/Wiley-Interscience, New York, NY

Babiarz JE, Halley JE, Rine J (2006) Telomeric heterochromatin boundaries require NuA4-dependent acetylation of histone variant H2AZ in Saccharomyces cerevisiae. Genes Dev 20:700-710

Barbaric S, Reinke H, Hörz W (2003) Multiple mechanistically distinct functions of SAGA at the PHO5 promoter. Mol Cell Biol 23:3468-3476

Beamish HJ, Jessberger R, Riballo E, Priestley A, Blunt T, Kysela B, Jeggo P (2000) The C-terminal conserved domain of DNA-PKcs, missing in the SCID mouse, is required for kinase activity. Nucleic Acids Res 28:1506-1513

Berger SL, Pina B, Silverman N, Marcus GA, Agapite J, Regier JL, Triezenberg SJ, Guarente L (1992) Genetic isolation of ADA2: a potential transcriptional adaptor required for function of certain acidic activation domains. Cell 70:251-265

Bhaumik SR, Green MR (2001) SAGA is an essential in vivo target of the yeast acidic activator Gal4p. Genes Dev 15:1935-1945

Bhaumik SR, Green MR (2002) Differential requirement of SAGA components for recruitment of TATA-box-binding protein to promoters in vivo. Mol Cell Biol 22:7365-7371

Bhaumik SR, Raha T, Aiello DP, Green MR (2004) In vivo target of a transcriptional activator revealed by fluorescence resonance energy transfer. Genes Dev 18:333-343

Bird AW, Yu DY, Pray-Grant MG, Qiu Q, Harmon KE, Megee PC, Grant PA, Smith MM, Christman MF (2002) Acetylation of histone $\mathrm{H} 4$ by Esa1 is required for DNA double-strand break repair. Nature 419:411-415

Bosotti R, Isacchi A, Sonnhammer EL (2000) FAT: a novel domain in PIK-related kinases. Trends Biochem Sci 25:225-227

Brandl CJ, Furlanetto AM, Martens JA, Hamilton KS (1993) Characterization of $N G G 1$, a novel yeast gene required for glucose repression of GAL4p-regulated transcription. EMBO J 12:52555265

Brown CE, Howe L, Sousa K, Alley SC, Carrozza MJ, Tan S, Workman JL (2001) Recruitment of HAT complexes by direct activator interactions with the ATM-related Tra1 subunit. Science 292:2333-2337

Burgess JR, Zhou H, Han J, Zhang Z (2010) A role for Gcn5 in replication-coupled nucleosome assembly. Mol Cell 37:469-480 
Chen W, Struhl K (1988) Saturation mutagenesis of a yeast HIS3 "TATA element": genetic evidence for a specific TATA-binding protein. Proc Natl Acad Sci USA 85:843-851

Choy JS, Kron SJ (2002) NuA4 subunit Yng2 function in intra-S-phase DNA damage response. Mol Cell Biol 22:8215-8225

Cross FR (1997) 'Marker swap' plasmids: convenient tools for budding yeast molecular genetics. Yeast 13:647-653

Dames SA, Mulet JM, Rathgeb-Szabo K, Hall MN, Grzesiek S (2005) The solution structure of the FATC domain of the protein kinase target of rapamycin suggests a role for redox-dependent structural and cellular stability. J Biol Chem 280:20558-20564

Downs JA, Allard S, Jobin-Robitaille O, Javaheri A, Auger A, Bouchard N, Kron SJ, Jackson SP, Côté J (2004) Binding of chromatin-modifying activities to phosphorylated histone $\mathrm{H} 2 \mathrm{~A}$ at DNA damage sites. Mol Cell 16:979-990

Dudley AM, Rougeulle C, Winston F (1999) The Spt components of SAGA facilitate TBP binding to a promoter at a post-activatorbinding step in vivo. Genes Dev 13:2940-2945

Eberharter A, Sterner DE, Schieltz D, Hassan A, Yates JR 3rd, Berger SL, Workman JL (1999) The ADA complex is a distinct histone acetyltransferase complex in Saccharomyces cerevisiae. Mol Cell Biol 19:6621-6631

Eisen MB, Spellman PT, Brown PO, Botstein D (1998) Cluster analysis and display of genome-wide expression patterns. Proc Natl Acad Sci USA 95:14863-14868

Evan GI, Lewis GK, Ramsay G, Bishop JM (1985) Isolation of monoclonal antibodies specific for human c-myc proto-oncogene product. Mol Cell Biol 5:3610-3616

Fishburn J, Mohibullah N, Hahn S (2005) Function of a eukaryotic transcription activator during the transcription cycle. Mol Cell 18:369-378

Gansheroff LF, Dollard C, Tan P, Winston F (1995) The Saccharomyces cerevisiae $S P T 7$ gene encodes a very acidic protein important for transcription in vivo. Genetics 139:523-536

Gasch AP, Spellman PT, Kao CM, Carmel-Harel O, Eisen MB, Storz G, Botstein D, Brown PO (2000) Genomic expression programs in the response of yeast cells to environmental changes. Mol Biol Cell 11:4241-4257

Ghaemmaghami S, Huh WK, Bower K, Howson RW, Belle A, Dephoure N, O'Shea EK, Weissman JS (2003) Global analysis of protein expression in yeast. Nature 425:737-741

Govind CK, Zhang F, Qiu H, Hofmeyer K, Hinnebusch AG (2007) Gen5 promotes acetylation, eviction, and methylation of nucleosomes in transcribed coding regions. Mol Cell 25:31-42

Grant PA, Duggan L, Côté J, Roberts SM, Brownell JE, Candau R, Ohba R, Owen-Hughes T, Allis CD, Winston F, Berger SL, Workman JL (1997) Yeast Gen5 functions in two multisubunit complexes to acetylate nucleosomal histones: characterization of an Ada complex and the SAGA (Spt/Ada) complex. Genes Dev 11:1640-1650

Han M, Grunstein M (1988) Nucleosome loss activates yeast downstream promoters in vivo. Cell 55:1137-1145

Harbison CT, Gordon DB, Lee TI, Rinaldi NJ, Macisaac KD, Danford TW, Hannett NM, Tagne JB, Reynolds DB, Yoo J, Jennings EG, Zeitlinger J, Pokholok DK, Kellis M, Rolfe PA, Takusagawa KT, Lander ES, Gifford DK, Fraenkel E, Young RA (2004) Transcriptional regulatory code of a eukaryotic genome. Nature 431:99-104

Henry KW, Wyce A, Lo WS, Duggan LJ, Emre NC, Kao CF, Pillus L, Shilatifard A, Osley MA, Berger SL (2003) Transcriptional activation via sequential histone $\mathrm{H} 2 \mathrm{~B}$ ubiquitylation and deubiquitylation, mediated by SAGA-associated Ubp8. Genes Dev 17:2648-2663

Herceg Z, Hulla W, Gell D, Cuenin C, Lleonart M, Jackson S, Wang JQ (2001) Disruption of Trrap causes early embryonic lethality and defects in cell cycle progression. Nat Genet 29:206-211
Hoke SM, Genereaux J, Liang G, Brandl CJ (2008a) A conserved central region of yeast Ada2 regulates the histone acetyltransferase activity of Gen5 and interacts with phospholipids. J Mol Biol 384:743-755

Hoke SM, Guzzo J, Andrews B, Brandl CJ (2008b) Systematic genetic array analysis links the Saccharomyces cerevisiae SAGA/SLIK and NuA4 component Tra1 to multiple cellular processes. BMC Genet 9:46

Holstege FC, Jennings EG, Wyrick JJ, Lee TI, Hengartner CJ, Green MR, Golub TR, Lander ES, Young RA (1998) Dissecting the regulatory circuitry of a eukaryotic genome. Cell 95:717-728

Hughes TR, Marton MJ, Jones AR, Roberts CJ, Stoughton R, Armour CD, Bennett HA, Coffey E, Dai H, He YD, Kidd MJ, King AM, Meyer MR, Slade D, Lum PY, Stepaniants SB, Shoemaker DD, Gachotte D, Chakraburtty K, Simon J, Bard M, Friend SH (2000) Functional discovery via a compendium of expression profiles. Cell 102:109-126

Huisinga KL, Pugh BF (2004) A genome-wide housekeeping role for TFIID and a highly stress regulated role for SAGA in Saccharomyces cerevisiae. Mol Cell 13:573-585

Ingvarsdottir K, Krogan NJ, Emre NC, Wyce A, Thompson NJ, Emili A, Hughes TR, Greenblatt JF, Berger SL (2005) H2B ubiquitin protease Ubp8 and Sgf11 constitute a discrete functional module within the Saccharomyces cerevisiae SAGA complex. Mol Cell Biol 25:1162-1172

Jiang X, Sun Y, Chen S, Roy K, Price BD (2006) The FATC domains of PIKK proteins are functionally equivalent and participate in the Tip60-dependent activation of DNA-PKes and ATM. J Biol Chem 281:15741-15746

Kohler A, Pascual-Garcia P, Llopis A, Zapater M, Posas F, Hurt E, Rodriguez-Navarro $S$ (2006) The mRNA export factor Sus1 is involved in Spt/Ada/Gcn5 acetyltransferase-mediated H2B deubiquitinylation through its interaction with Ubp8 and Sgf11. Mol Biol Cell 17:4228-4236

Kohler A, Schneider M, Cabal CG, Nehrbass U, Hurt E (2008) Yeast Ataxin-7 links histone deubiquitination with gene gating and mRNA export. Nat Cell Biol 10:707-715

Krogan NJ, Keogh MC, Datta N, Sawa C, Ryan OW, Ding H, Haw RA, Pootoolal J, Tong A, Canadien Z, Richards DP, Wu X, Emili A, Hughes TR, Buratowski S, Greenblatt JF (2003) A Snf2 family ATPase complex required for recruitment of the histone $\mathrm{H} 2 \mathrm{~A}$ variant Htz1. Mol Cell 12:1565-1576

Krogan NJ, Baetz K, Keogh MC, Datta N, Sawa C, Kwok TC, Thompson NJ, Davey MG, Pootoolal J, Hughes TR, Emili A, Buratowski S, Hieter P, Greenblatt JF (2004) Regulation of chromosome stability by the histone H2A variant Htz1, the Swr1 chromatin remodeling complex, and the histone acetyltransferase NuA4. Proc Natl Acad Sci USA 101:13513-13518

Larschan E, Winston F (2001) The S. cerevisiae SAGA complex functions in vivo as a coactivator for transcriptional activation by Gal4. Genes Dev 15:1946-1956

Larschan E, Winston F (2005) The Saccharomyces cerevisiae Srb8Srb11 complex functions with the SAGA complex during Gal4activated transcription. Mol Cell Biol 24:114-123

Le Masson I, Yu DY, Jensen K, Chevalier A, Courbeyrette R, Boulard Y, Smith MM, Mann C (2003) Yaf9, a novel NuA4 histone acetyltransferase subunit, is required for the cellular response to spindle stress in yeast. Mol Cell Biol 23:6086-6102

Lieb JD, Liu X, Botstein D, Brown PO (2001) Promoter-specific binding of Rap1 revealed by genome-wide maps of protein-DNA association. Nat Genet 28:327-334

Lin YY, Qi Y, Lu JY, Pan X, Yuan DS, Zhao Y, Bader JS, Boeke JD (2008) A comprehensive synthetic genetic interaction network governing yeast histone acetylation and deacetylation. Genes Dev 22:2062-2074 
Lu J, Wong JJ, Edwards RA, Manchak J, Frost LS, Glover JNM (2008) Structural basis of specific TraD-TraM recognition during F plasmid-mediated bacterial conjugation. Mol Microbiol 70:89-99

Lundblad V, Szostak JW (1989) A mutant with a defect in telomere elongation leads to senescence in yeast. Cell 57:633-643

Mao X, Hu Y, Liang C, Lu C (2002) MET3 promoter: a tightly regulated promoter and its application in construction of conditional lethal strain. Curr Microbiol 45:37-40

Martinez-Pastor MT, Marchler G, Schuller C, Marchler-Bauer A, Ruis H, Estruch F (1996) The Saccharomyces cerevisiae zinc finger proteins Msn2p and Msn4p are required for transcriptional induction through the stress response element (STRE). EMBO J 15:2227-2235

McMahon SB, Van Buskirk HA, Dugan KA, Copeland TD, Cole MD (1998) The novel ATM-related protein TRRAP is an essential cofactor for the c-Myc and E2F oncoproteins. Cell 94:363-374

Millar CB, Xu F, Zhang K, Grunstein M (2006) Acetylation of H2AZ Lys 14 is associated with genome-wide gene activity in yeast. Genes Dev 20:711-722

Mitchell L, Lambert JP, Gerdes M, Al-Madhoun AS, Skerjanc IS, Figeys D, Baetz K (2008) Functional dissection of the NuA4 histone acetyltransferase reveals its role as a genetic hub and that Eaf1 is essential for complex integrity. Mol Cell Biol 28:2244-2256

Mohibullah N, Hahn S (2008) Site-specific cross-linking of TBP in vivo and in vitro reveals a direct functional interaction with the SAGA subunit Spt3. Genes Dev 22:2994-3006

Morita T, Yamashita A, Kashima I, Ogata K, Ishiura S, Ohno S (2007) Distant $\mathrm{N}$ - and $\mathrm{C}$-terminal domains are required for intrinsic kinase activity of SMG-1, a critical component of nonsense-mediated mRNA decay. J Biol Chem 282:7799-7808

Mortazavi A, Williams BA, McCue K, Schaeffer L, Wold B (2008) Mapping and quantifying mammalian transcriptomes by RNASeq. Nat Methods 5:621-628

Murr R, Vaissiere T, Sawan C, Shukla V, Herceg Z (2007) Orchestration of chromatin-based processes: mind the TRRAP. Oncogene 26:5358-5372

Mutiu AI, Brandl CJ (2005) RNA isolation from yeast using silica matrices. J Biomol Tech 16:316-317

Mutiu AI, Hoke SM, Genereaux J, Hannam C, MacKenzie K, JobinRobitaille O, Guzzo J, Côté J, Andrews B, Haniford DB, Brandl CJ (2007a) Structure/function analysis of the phosphatidylinositol-3-kinase domain of yeast Tra1. Genetics 177:151-166

Mutiu AI, Hoke SM, Genereaux J, Liang G, Brandl CJ (2007b) The role of histone ubiquitylation and deubiquitylation in gene expression as determined by the analysis of an HTB1(K123R) Saccharomyces cerevisiae strain. Mol Genet Gen 277:491-506

Nourani AR, Utley RT, Allard S, Côté J (2004) Recruitment of the NuA4 complex poises the PHO5 promoter for chromatin remodeling and activation. EMBO J 23:2597-2607

Priestley A, Beamish HJ, Gell D, Amatucci AG, Muhlmann-Diaz MC, Singleton BK, Smith GC, Blunt T, Schalkwyk LC, Bedford JS, Jackson SP, Jeggo PA, Taccioli GE (1998) Molecular and biochemical characterization of DNA-dependent protein kinasedefective rodent mutant irs-20. Nucleic Acids Res 26:1965-1973

Reeves WM, Hahn S (2005) Targets of the Gal4 transcription activator in functional transcription complexes. Mol Cell Biol 25:90929102

Reid JL, Iyer VR, Brown PO, Struhl K (2000) Coordinate regulation of yeast ribosomal protein genes is associated with targeted recruitment of Esa1 histone acetylase. Mol Cell 6:1297-1307

Rigaut G, Shevchenko A, Rutz B, Wilm M, Mann M, Seraphin B (1999) A generic protein purification method for protein complex characterization and proteome exploration. Nat Biotechnol 17:1030-1032

Rudra D, Zhao Y, Warner JR (2005) Central role of Ifh1p-Fhl1p interaction in the synthesis of yeast ribosomal proteins. EMBO J 24:533-542

Ruiz-Garcia AB, Sendra R, Pamblanco M, Tordera V (1997) Gen5p is involved in the acetylation of histone $\mathrm{H} 3$ in nucleosomes. FEBS Lett 403:186-190

Saleh A, Lang V, Cook R, Brandl CJ (1997) Identification of native complexes containing the yeast coactivator/repressor proteins Ngg1/Ada3 and Ada2. J Biol Chem 272:5571-5578

Saleh A, Schieltz D, Ting N, McMahon SB, Litchfield DW, Yates JR 3rd, Lees-Miller SP, Cole MD, Brandl CJ (1998) Tra1p is a component of the yeast AdaSpt transcriptional regulatory complexes. J Biol Chem 273:26559-26565

Shevchenko A, Roguev A, Schaft D, Buchanan L, Habermann B, Sakalar C, Thomas H, Krogan NJ, Stewart AF (2008) Chromatin Central: towards the comparative proteome by accurate mapping of the yeast proteomic environment. Genome Biol 9:R167

Spagnolo L, Rivera-Calzada A, Pearl LH, Llorca O (2006) Threedimensional structure of the human DNA-PKcs/Ku70/Ku80 complex assembled on DNA and its implications for DNA DSB repair. Mol Cell 22:511-519

Sterner DE, Grant PA, Roberts SM, Duggan LJ, Belotesrkovskaya R, Pacella LA, Winston F, Workman JL, Berger SL (1999) Functional organization of the yeast SAGA complex: distinct components involved in structural integrity, nucleosome acetylation, and TATA-Binding protein interaction. Mol Cell Biol 19:86-98

Suka N, Suka Y, Carmen AA, Wu J, Grunstein M (2001) Highly specific antibodies determine histone acetylation site usage in yeast heterochromatin and euchromatin. Mol Cell 8:473-479

Sun Y, Jiang X, Chen S, Fernandes N, Price BD (2005) A role for the Tip60 histone acetyltransferase in the acetylation and activation of ATM. Proc Natl Acad Sci USA 102:13182-13187

Sun Y, Xu Y, Roy K, Price BD (2007) DNA damage-induced acetylation of lysine 3016 of ATM activates ATM kinase activity. Mol Cell Biol 27:8502-8509

Takahashi T, Hara K, Inoue H, Kawa Y, Tokunaga C, Hidayat S, Yoshino K, Kuroda Y, Yonezawa K (2000) Carboxyl-terminal region conserved among phosphoinositide-kinase-related kinases is indispensable for mTOR function in vivo and in vitro. Genes Cells 5:765-775

Tonikian R, Zhang Y, Sazinsky SL, Currell B, Yeh JH, Reva B, Held HA, Appleton BA, Evangelista M, Wu Y, Xin X, Chan AC, Seshagiri S, Sander C, Lasky LA, Boone C, Bader GD, Sidhu SS (2008) A specificity map for the PDZ domain family. PLoS Biol 6:e239

Vassilev A, Yamauchi J, Kotani T, Prives C, Avantaggiati ML, Qin J, Nakatani Y (1998) The $400 \mathrm{kDa}$ subunit of the PCAF histone acetylase complex belongs to the ATM superfamily. Mol Cell 2:869-875

Winzeler EA, Davis RW (1997) Functional analysis of the yeast genome. Curr Opin Genet Dev 7:771-776

Wu PY, Winston F (2002) Analysis of Spt7 function in the Saccharomyces cerevisiae SAGA coactivator complex. Mol Cell Biol 22:5367-5379

Yu MC, Bachand F, McBride AE, Komili S, Casolari JM, Silver PA (2004) Arginine methyltransferase affects interactions and recruitment of mRNA processing and export factors. Genes Dev 18:2024-2035 